Economics Working Paper Series

2015/017

\title{
The Joint Labor Supply Decision of Married Couples and the Social Security Pension System
} Shinichi Nishiyama

The Department of Economics

Lancaster University Management School

Lancaster LA1 4YX

UK

(C) Authors

All rights reserved. Short sections of text, not to exceed two paragraphs, may be quoted without explicit permission, provided that full acknowledgement is given. 


\title{
The Joint Labor Supply Decision of Married Couples and the Social Security Pension System*
}

\author{
Shinichi Nishiyama ${ }^{\dagger}$ \\ Lancaster University
}

August 14, 2015

\begin{abstract}
The current U.S. Social Security program redistributes resources from high-wage workers to low-wage workers through its progressive benefit schedule and from two-earner couples and singles to one-earner couples through its spousal and survivors benefits. This paper extends a standard general-equilibrium overlapping-generations model with uninsurable wage shocks to analyze the effect of the spousal and survivors benefits on the labor supply of married households and the overall economy. The heterogeneousagent model calibrated to the current U.S. economy predicts that, in the long run, removing spousal and survivors benefits would increase the female labor participation rate by $1.4 \%$, the total working hours of women by $1.6-1.7 \%$, and the total output of the economy by $0.5-0.6 \%$. Under the balanced-budget assumption, a phased-in cohort-by-cohort removal of these benefits would make all age cohorts, on average, better off, although the policy change would make a majority of young married households worse off in the short run.
\end{abstract}

JEL Classification Numbers: D91, E62, H55.

Key Words: dynamic general equilibrium; heterogeneous agents; overlapping generations; female labor supply.

\footnotetext{
${ }^{*}$ For their helpful comments and suggestions, the author thanks Karen Kopecky, and the seminar/conference participants at the Michigan Retirement Research Center, Federal Reserve Bank of Atlanta, Georgia State University, Midwest Macroeconomics Meetings, Econometric Society North American Summer Meeting, Society for Computational Economics CEF Meeting, Society for Economic Dynamics Annual Meeting, Emory University, Kansas State University, Bank of Canada, Congressional Budget Office, Hitotsubashi University, Kansai University, Tohoku University, Lancaster University, University of Queensland, and Florida State University. The author is responsible for any remaining errors. This study was supported by a grant from the Social Security Administration through the Michigan Retirement Research Center (Grant \#10-M-98362-5-01). The findings and conclusions expressed in this study are solely those of the author and do not represent the views of the Social Security Administration, any agency of the Federal government, or the Michigan Retirement Research Center.

${ }^{\dagger}$ Department of Economics, Lancaster University Management School, Lancaster, LA1 4YX, United Kingdom. E-mail: s.nishiyama@lancaster.ac.uk.
} 


\section{Introduction}

The current Old-Age and Survivors Insurance (OASI) program of the U.S. Social Security system redistributes resources from high-wage workers to low-wage workers through its progressive benefit schedule and from two-earner couples and singles to one-earner couples through spousal and survivors benefits. Due to computational difficulty, most previous literature on the dynamic general-equilibrium analyses of Social Security does not explicitly consider the redistribution between one-earner households and two-earner households 1 However, because the effective payroll tax rate of secondary earners is higher in an economy that provides spousal and survivors benefits, the exclusion of spousal and survivors benefits in the model economy causes the model to potentially underestimate the labor supply distortion of the OASI payroll tax.

This paper extends a standard dynamic general equilibrium overlapping-generations (OLG) model with uninsurable wage shocks by implementing the joint labor supply decision of married couples. Assuming the spousal and survivors benefits under current law, this paper calibrates the heterogeneous-agent model to the U.S. economy in recent years. Then, it analyzes to what extent the spousal and survivors benefits distort the labor supply decision of married households and examines whether the government can improve the social welfare without significantly reducing the insurance aspect of the current Social Security OASI program.

In the model economy, households are heterogeneous with respect to their marital status, age, wealth, the husband's wage rate, the wife's wage rate, the husband's average historical earnings, and the wife's average historical earnings. In each period, which is a year in the model economy, a working-age household receives idiosyncratic wage shocks — one for the husband and another for the wife if married—and jointly determines its consumption, working hours, and end-of-period wealth to maximize their rest-of-the-lifetime utility, taking factor prices and government policy schedule as given.

This paper first constructs a baseline economy, which is on a balanced growth path, with the current OASI system that includes spousal and survivors benefits. Then, the paper assumes that the government removes the spousal and survivors benefits in a cohort-by-cohort phased-in manner, and it solves the model for equilibrium transition paths under a couple of the government's financing assumptions. Regarding the Social Security budget, this paper assumes that it is separated from the rest of the government budget and that workers' own benefits (OA benefits) are increased proportionally to balance the budget, keeping the payroll

\footnotetext{
${ }^{1}$ For example, Auerbach and Kotlikoff (1987), İmrohoroğlu, İmrohoroğlu, and Joines (1995), Kotlikoff, Smetters, and Walliser (1999), Conesa and Krueger (1999), Nishiyama and Smetters (2007), and Huggett and Para (2010) all assume single-worker households in their model economies.
} 
tax rate unchanged. Regarding the rest of the government budget, this paper assumes the government either increases lump-sum transfer payments or reduces marginal income tax rates to balance the budget after the policy change.

The main findings in this paper are as follows: If the spousal and survivors benefits were removed, in the long run, the female labor participation rate would increase by $1.4 \%$, the average working hours of female workers would increase by $0.2-0.3 \%$, depending on the government financing assumption, and the total working hours of women would increase by $1.6-1.7 \%$. The total working hours of men would decrease by $0.3 \%$, however, because of the intrafamilial substitution. The total labor supply in efficiency units would increase by $0.3-0.4 \%$, the capital stock would increase by $0.8-1.0 \%$, and the gross domestic product would also increase by $0.5-0.6 \%$. The macroeconomic effect would be larger if the government cut marginal income tax rates to balance the rest of the government budget rather than increasing lump-sum transfers.

Because of the higher economic activity and the lower distortion from the Social Security benefit schedule, future newborn (age-21) households would be, on average, better off by $0.4-0.5 \%$ in the long run with the consumption equivalence measure. The welfare effect of the policy change would be greater (better) if the government balanced the rest of its budget by increasing lump-sum transfer payments. The phased-in removal of spousal and survivors benefits would make all age cohorts over the transition path, on average, better off under both financing assumptions, although the policy change would make a majority of young married households worse off in the short run.

To the best of my knowledge, few studies have used a large-scale dynamic general-equilibrium OLG model to analyze the effect of spousal and survivors benefits on the labor supply of married households, the macro economy, and social welfare. Kaygusuz (2014) is probably the first study that constructs a heterogeneous-agent OLG model to explicitly analyze the effect of spousal and survivors' benefits. Yet, the present paper is different from Kaygusuz's in several aspects: the present paper assumes uninsurable idiosyncratic wage shocks in the model economy ${ }^{2}$ and solves the model for an equilibrium transition path to check if the removal of these benefits, even in the short run, are welfare improving $\mathrm{H}^{3}$

Kaygusuz (2010) and Guner, Kaygusuz, and Ventura (2012a, 2012b) construct a deterministic generalequilibrium OLG model with heterogeneous married and single households, similar to Kaygusuz (2014),

\footnotetext{
${ }^{2}$ If a husband and a wife are not certain about their future market wages and thus their own social security benefits, a possible labor supply distortion caused by the spousal and survivors benefits will be attenuated especially when they are young.

${ }^{3}$ It is well known that partial privatization of the Social Security pension, for example, would hurt current generations through its transition costs, even though future generations would gain from the reform in the long run.
} 
and these papers instead analyze the effect of the U.S. income tax system on the female labor supply. Hong and Ríos-Rull (2007) also construct a heterogeneous-agent OLG model of married and single households to analyze the welfare effect of Social Security in the presence/absence of life insurance and annuity markets. However, in their model, the household's labor supply is inelastic, the age-earning profiles of the workers are deterministic, and Social Security benefits are uniform and independent of the household's earning histories $4^{4}$ Thus, the present paper contributes to the current literature by demonstrating how married couples react to a future Social Security benefit schedule by both choosing their optimal labor supply and saving.

The present paper is also related to recent studies on the female labor supply with a partial-equilibrium life cycle model. Olivetti (2006) constructs a life cycle model of married couples that includes the home production of child care and learning-by-doing type human capital accumulation, and she analyzes the importance of these factors on the increase in women's market work hours. Attanasio, Low, and SánchezMarcos (2008) also construct a life cycle model of the female labor participation (the male labor supply is assumed to be inelastic). They explain how the female labor supply has been changed by the declining cost of raising children and labor participation. They assume that the earnings of the husband and wife are subject to positively correlated permanent shocks. Similar to these studies, the present paper assumes unitary households - perfectly altruistic married couples—but focus more on the household's reaction to the current and future OASI policy. More recently, Bethencourt and Sánchez-Marcos (2014) construct a partial-equilibrium life cycle model with married and widowed households, and they analyze the effect of the U.S. Social Security system, including survivors benefits, on female labor participation rates.

The rest of this paper is presented as follows: Section 2 describes the heterogeneous-agent OLG model with the joint decision-making of married couples, Section 3 shows the calibration of the baseline economy to the U.S. economy, Section 4 explains the effects of removing spousal and survivors benefits in equilibrium transition paths, Section 5 examines the robustness of the model, and Section 6 concludes the paper. The appendix describes the computational algorithm used to solve the household's optimization problem.

\section{The Model Economy}

The economy consists of a large number of overlapping-generations households, a perfectly competitive representative firm with constant-returns-to-scale technology, and a government with a commitment

\footnotetext{
${ }^{4}$ Their model assumes that a married couple receives $150 \%$ of the average male benefit and that a widow receives $100 \%$ of the average male benefit.
} 
technology. Time is discrete and one model period is a year.

\subsection{The Households}

There are three types of households in the model economy: married households where the husband and wife are both alive $(m=0)$, single-male (never married or widowered) households $(m=1)$, and singlefemale (never married or widowed) households $(m=2)$. The households, both married and single, enter the economy at age $i=21$. For simplicity, the husband and wife of each married household are of the same age. In the model economy, a fixed proportion $\eta$ of men and women are married when they enter the economy at age 21 and never divorce, and $1-\eta$ of men and women are single and never marry $5^{5}$ They start receiving Social Security benefits at age $I_{R}$ and live to at most age $I=100$.

The households are heterogeneous with respect to the marital status, $m=\{0,1,2\}$; the age, $i=$ $21, \ldots, I$; the beginning-of-period wealth, $a \in A=\left[a_{\min }, a_{\max }\right]$; the average historical earnings of the husband $(m=0)$ or the single male $(m=1), b_{1} \in B=\left[0, b_{\max }\right]$; the average historical earnings of the wife $(m=0)$ or the single female $(m=2), b_{2} \in B$; the earning ability of the husband or the single male, $e_{1} \in E=\left[0, e_{\max }\right]$; and the earning ability of the wife or the single female, $e_{2} \in E$. In each period, $t$, a married household receives earning ability shocks, $e_{1}$ and $e_{2}$, and chooses joint consumption, $c$, the husband's hours of market work, $h_{1}$, the wife's hours of market work, $h_{2}$, and the end-of-period joint wealth, $a^{\prime}$, to maximize their expected lifetime utility. Similarly, a single household receives earning ability shocks, $e_{1}$ or $e_{2}$, and chooses consumption spending, $c$, the hours of market work, $h_{1}$ or $h_{2}$, and the end-of-period wealth, $a^{\prime}$, to maximize his or her expected lifetime utility.

The average historical earnings approximate the average indexed monthly earnings (AIME). These historical earnings determine the primary insurance amounts (PIA) of Social Security pension. The earning abilities of the husband and wife follow the first-order Markov process, and these are correlated to each other but independent of the mortality shocks. The PIA of a married or widow(er)ed household is calculated separately for the husband and wife. For a married elderly household $(m=0)$, the secondary earner receives either his or her own old-age retirement benefit or the spousal benefit (50\% of the spouse's old-age benefit), whichever is higher. For a widow(er)ed elderly household ( $m=1$ or 2 ), the survivor receives either his or her own old-age benefit or the survivors benefit (100\% of the spouse's old-age benefit), whichever is higher 6

\footnotetext{
${ }^{5}$ When $\eta=0.75$, the share of married households is $\eta /(\eta+2(1-\eta))=0.60$, which is roughly consistent with the U.S. economy.

${ }^{6}$ For more detailed descriptions of the Social Security (OASDI) program, see, for example, pp.9-19 of Social Security Admin-
} 
State Variables. Let $\mathbf{s}$ and $\mathbf{S}_{t}$ be the individual state of a household and the aggregate state of the economy in year $t$, respectively,

$$
\mathbf{s}=\left(i, a, b_{1}, b_{2}, e_{1}, e_{2}, m\right), \quad \mathbf{S}_{t}=\left(x(\mathbf{s}), W_{G, t}\right),
$$

where $x(\mathbf{s})$ is the population density function of households, and $W_{G, t}$ is the government net worth at the beginning of year $t$. Let $\boldsymbol{\Psi}_{t}$ be the government policy schedule as of year $t$,

$$
\mathbf{\Psi}_{t}=\left\{C_{G, s}, \operatorname{tr}_{L S, s}, \tau_{I, s}(\cdot), \tau_{P, s}(\cdot), \operatorname{tr}_{S S, s}(\cdot), W_{G, s+1}, q_{s}\right\}_{s=t}^{\infty}
$$

where $C_{G, t}$ is government consumption, $\operatorname{tr}_{L S, t}$ is a lump sum transfer to each adult family member, $\tau_{I, t}(\cdot)$ is a progressive income tax function, $\tau_{P, t}(\cdot)$ is a Social Security payroll tax function, $\operatorname{tr}_{S S, t}(\cdot)$ is a Social Security benefit function, $W_{G, t+1}$ is the government net worth at the beginning of the next year, and $q_{t}$ is an accidental bequest distributed through the government.

The Optimization Problem. Let $v\left(\mathbf{s}, \mathbf{S}_{t} ; \mathbf{\Psi}_{t}\right)$ be the value function of a heterogeneous household at the beginning of year $t$. The household's optimization problem is then

$$
\begin{aligned}
v\left(\mathbf{s}, \mathbf{S}_{t} ; \mathbf{\Psi}_{t}\right)=\max _{c, h_{1}, h_{2}}\left\{u\left(c, h_{1}, h_{2} ; m, n_{m, i}\right)+\chi\left(h_{1}, h_{2} ; m, n_{m, i}\right)\right. \\
\left.\quad+\tilde{\beta} \sum_{m^{\prime}=0}^{2} \int_{E^{2}} v\left(\mathbf{s}^{\prime}, \mathbf{S}_{t+1} ; \boldsymbol{\Psi}_{t+1}\right) d \Pi_{i}\left(e_{1}^{\prime}, e_{2}^{\prime}, m^{\prime} \mid e_{1}, e_{2}, m\right)\right\}
\end{aligned}
$$

subject to the constraints for the decision variables,

(2) $\quad c>0$

(3) $0 \leq h_{1}<1 \quad$ if $m \neq 2, \quad h_{1}=0$ if $m=2$,

(4) $0 \leq h_{2}<1-\kappa n_{m, i}$ if $m \neq 1, \quad h_{2}=0$ if $m=1$,

and the law of motion of the individual state,

(5) $\mathbf{s}^{\prime}=\left(i+1, a^{\prime}, b_{1}^{\prime}, b_{2}^{\prime}, e_{1}^{\prime}, e_{2}^{\prime}, m^{\prime}\right)$,

istration (2014). 


$$
\begin{aligned}
a^{\prime} & =\frac{1}{1+\mu}\left[\left(1+r_{t}\right) a+w_{t} e_{1} h_{1}+w_{t} e_{2} h_{2}-\tau_{I, t}\left(r_{t} a+w_{t} e_{1} h_{1}+w_{t} e_{2} h_{2} ; m, n_{m, i}\right)\right. \\
& \left.-\tau_{P, t}\left(w_{t} e_{1} h_{1}, w_{t} e_{2} h_{2}\right)+\operatorname{tr}_{S S, t}\left(i, b_{1}, b_{2}, m\right)+\left(1+\mathbf{1}_{\{m=0\}}\right)\left(\operatorname{tr}_{L S, t}+\mathbf{1}_{\left\{i<I_{R}\right\}} q_{t}\right)-c\right] \geq a_{\min }^{\prime}(\mathbf{s}), \\
\text { (7) } \quad b_{1}^{\prime} & =\mathbf{1}_{\left\{i<I_{R}, m \neq 2\right\}} \frac{1}{i-20}\left[(i-21) b_{1}+\min \left(w_{t} e_{1} h_{1}, \vartheta_{\max }\right)\right]+\mathbf{1}_{\left\{i \geq I_{R} \text { or } m=2\right\}} b_{1}, \\
\text { (8) } \quad b_{2}^{\prime} & =\mathbf{1}_{\left\{i<I_{R}, m \neq 1\right\}} \frac{1}{i-20}\left[(i-21) b_{2}+\min \left(w_{t} e_{2} h_{2}, \vartheta_{\max }\right)\right]+\mathbf{1}_{\left\{i \geq I_{R} \text { or } m=1\right\}} b_{2},
\end{aligned}
$$

where $u(\cdot)$ is a period utility function, $n_{m, i}$ is the average number of newborn babies by age, $\chi(\cdot)$ is a random variable of utility from staying at home, $\tilde{\beta}$ is the growth-adjusted time discount factor, $\Pi_{i}(\cdot \mid \cdot)$ is the transition probability function of exogenous state variables, and $\kappa$ is the time cost of childbirth and childcare per newborn baby, which is assumed only for a mother. In the budget constraint (the law of motion of $a$ ), $\mu$ is the long-run productivity growth rate, $r_{t}$ is the interest rate, $w_{t}$ is the wage rate per efficiency unit of labor, and $\mathbf{1}_{\{\cdot\}}$ is an indicator function that returns 1 if the condition in \{\} holds and 0 otherwise. This paper does not assume intergenerational bequest motives, and all working-age family members $\left(i<I_{R}\right)$ receive uniform accidental bequests, $q_{t}$. In the law of motion of $b_{1}$ and $b_{2}, \vartheta_{\max }$ are the maximum taxable earnings for the OASI program. To describe a balanced growth path by a steady-state equilibrium, individual variables other than working hours are normalized by using the long-run growth rate, $1+\mu$.

Preferences. The household's period utility function depends on the marital status. The utility function of a single household ( $m=1$ or 2 ) is a combination of Cobb-Douglas and constant relative risk aversion,

$$
u\left(c, h_{1}, h_{2} ; m=j, n_{m, i}\right)=\tilde{u}_{j}\left(c, h_{j} ; n_{j, i}\right)= \begin{cases}\frac{\left[c^{\alpha}\left(1-h_{1}\right)^{1-\alpha}\right]^{1-\gamma}}{1-\gamma} & \text { if } j=1 \\ \frac{\left[c^{\alpha}\left(1-\kappa n_{2, i}-h_{2}\right)^{1-\alpha}\right]^{1-\gamma}}{1-\gamma} & \text { if } j=2\end{cases}
$$

where the time cost parameter, $\kappa$, is used to replicate the average working hours of female workers relative to the hours of male workers. The utility function of a married household $(m=0)$ has the following additively separable form,

$$
u\left(c, h_{1}, h_{2} ; m=0, n_{m, i}\right)=\tilde{u}_{1}\left(\frac{c}{1+\lambda}, h_{1} ; 0\right)+\tilde{u}_{2}\left(\frac{c}{1+\lambda}, h_{2} ; n_{0, i}\right)
$$


where $1-\lambda \in[0,1]$ is the degree of joint consumption. All of the household consumption, $c$, is consumed jointly when $\lambda=0$, and all is consumed separately when $\lambda=17$ With this specification, the growthadjusted time discount factor is calculated as $\tilde{\beta}=\beta(1+\mu)^{\alpha(1-\gamma)}$ when $\beta$ is the unadjusted time discount factor.

The Utility from Staying at Home. The household receives additional utility from home-produced services when one of the adult family members stays at home, i.e., $h_{1}=0$ or $h_{2}=0$. The utility from staying at home, $\chi\left(h_{1}, h_{2} ; m, n_{m, i}\right)$, follows the Gamma distribution with parameters $\bar{\alpha}$ and $\left.\bar{\theta}\right]^{8}$ The two parameters are assumed to satisfy

$$
E(\chi)=\bar{\alpha} \bar{\theta}= \begin{cases}\kappa_{1} & \text { if }\left(m=0, h_{1}=0, h_{2}>0\right) \text { or }\left(m=1, h_{1}=0\right), \\ \kappa_{1}+n_{m, i} \kappa_{2} & \text { if }\left(m=0, h_{1} \geq 0, h_{2}=0\right) \text { or }\left(m=2, h_{2}=0\right),\end{cases}
$$

where the coefficient $\kappa_{1}$ indicates the utility from staying at home, and $\kappa_{2}$ indicates an additional utility from the mother's childbirth and childcare per newborn baby. Parameters, $\kappa_{1}$ and $\kappa_{2}$, are used to match the labor force participation rates of men and women ages $25-54$ in the model economy to the data. The scale parameter, $\bar{\theta}$, is set to be 2.0 thus $E(\chi)=\bar{\alpha} \bar{\theta}=2 \bar{\alpha}$ and $V(\chi)=\bar{\alpha} \bar{\theta}^{2}=4 \bar{\alpha} 9^{9}$

The State Transition Function. The model assumes that the husband's earning ability and the wife's earning ability are correlated to each other, but the deaths of the husband and wife are independent of each other. The exogenous state transition probability function is then described as

$$
\Pi_{i}\left(e_{1}^{\prime}, e_{2}^{\prime}, m^{\prime} \mid e_{1}, e_{2}, m\right)= \begin{cases}\Pi_{\left(e_{1}, e_{2}\right), i}\left(e_{1}^{\prime}, e_{2}^{\prime} \mid e_{1}, e_{2}\right) p_{m, i}\left(m^{\prime} \mid m\right) & \text { if } m=0 \\ \Pi_{e_{1}, i}\left(e_{1}^{\prime} \mid e_{1}\right) p_{m, i}\left(m^{\prime} \mid m\right) & \text { if } m=1 \\ \Pi_{e_{2}, i}\left(e_{2}^{\prime} \mid e_{2}\right) p_{m, i}\left(m^{\prime} \mid m\right) & \text { if } m=2,\end{cases}
$$

\footnotetext{
${ }^{7}$ The share of joint consumption in the total household consumption is calculated as $(1-\lambda) /(1+\lambda)$. In a general setting, the utility functions of a husband and wife can be defined separately, $u_{1}\left(c_{1}, c_{2}, h_{1}, h_{2}\right)=\tilde{u}_{1}\left(c_{1}, h_{1}\right)+\varphi \tilde{u}_{2}\left(c_{2}, h_{2}\right)$ and $u_{2}\left(c_{2}, c_{1}, h_{2}, h_{1}\right)=\tilde{u}_{2}\left(c_{2}, h_{2}\right)+\varphi \tilde{u}_{1}\left(c_{1}, h_{1}\right)$, where $\varphi \leq 1$ is the degree of altruism. The present study assumes that a married couple is perfectly altruistic, $\varphi=1$, and that their consumption is equal, $c_{1}=c_{2}=c /(1+\lambda)$. This paper then derives the unitary utility function of a married couple described above. Kotlikoff and Spivak (1981) and Brown and Poterba (2000) discuss the utility function of a married couple with the inelastic labor supply.

${ }^{8}$ This paper uses the Gamma random variable for the utility from staying at home, because the Gamma distribution has a formula to calculate the conditional expected value given one of the household's members chooses to stay at home, $E[\chi-d \mid \chi>d]$, and it is more flexible than the exponential distribution that has only one parameter.

${ }^{9}$ For $\bar{\theta}$ between 1.0 and 5.0, the choice of $\bar{\theta}$ affects the aggregate economy very little when $E(\chi)=\bar{\alpha} \bar{\theta}$ is kept unchanged.
} 
where $\Pi_{\left(e_{1}, e_{2}\right), i}(\cdot), \Pi_{e_{1}, i}(\cdot)$, and $\Pi_{e_{2}, i}(\cdot)$ are transition probability functions of earning ability. The transition probabilities of the marital status are determined solely by the mortality rates of men and women as

$$
\begin{array}{lll}
p_{m, i}(0 \mid 0)=\phi_{1, i} \phi_{2, i}, & p_{m, i}(1 \mid 0)=\phi_{1, i}\left(1-\phi_{2, i}\right), & p_{m, i}(2 \mid 0)=\left(1-\phi_{1, i}\right) \phi_{2, i}, \\
p_{m, i}(0 \mid 1)=0, & p_{m, i}(1 \mid 1)=\phi_{1, i}, & p_{m, i}(2 \mid 1)=0, \\
p_{m, i}(0 \mid 2)=0, & p_{m, i}(1 \mid 2)=0, & p_{m, i}(2 \mid 2)=\phi_{2, i},
\end{array}
$$

where $\phi_{1, i}$ and $\phi_{2, i}$ are the conditional survival rates of men and women, respectively, at the end of age $i$ given that they are alive at the beginning of age $i$.

The Income Tax Function. Let $y$ be the taxable income of a household,

$$
y=\max \left(r_{t} a+w_{t} e_{1} h_{1}+w_{t} e_{2} h_{2}-\left(1+\mathbf{1}_{\{m=0\}}\right) \xi, 0\right),
$$

where $\xi$ is the sum of the standard deduction and exemptions per adult family member. The individual income tax function is one of Gouveia and Strauss (1994),

$$
\tau_{I, t}(y ; m)=\varphi_{t}\left[y-\left(y^{-\varphi_{m, 1}}+\varphi_{m, 2}\right)^{-1 / \varphi_{m, 1}}\right]
$$

where the parameters (thus progressive tax rates) depend on the marital status: $m=0$ (married filing jointly) or $m=1,2$ (single).

Social Security Pensions. Let $y_{1}=w_{t} e_{1} h_{1}$ and $y_{2}=w_{t} e_{2} h_{2}$ be the earnings of the husband and the wife, respectively, and let $\vartheta_{\max }$ be the maximum taxable earnings for the OASI program. Then, the OASI payroll tax function is

$$
\tau_{P, t}\left(y_{1}, y_{2}\right)=\bar{\tau}_{P, t}\left[\min \left(y_{1}, \vartheta_{\max }\right)+\min \left(y_{2}, \vartheta_{\max }\right)\right]
$$

where $\bar{\tau}_{P, t}$ is a flat OASI tax rate that includes the employer portion of the tax. Let $\vartheta_{1}$ and $\vartheta_{2}$ be the thresholds for the 3 replacement rate brackets $(90 \%, 32 \%$, and 15\%) that calculate the primary insurance amount (PIA) from the average historical earnings. The PIA's of the husband and the wife, $\psi\left(i, b_{1}\right)$ and 
$\psi\left(i, b_{2}\right)$, are then

$$
\begin{aligned}
\psi\left(i, b_{j}\right)=\mathbf{1}_{\left\{i \geq I_{R}\right\}}(1+\mu)^{60-i}\left\{0.90 \min \left(b_{j}, \vartheta_{1}\right)\right. & \\
& \left.+0.32 \max \left[\min \left(b_{j}, \vartheta_{2}\right)-\vartheta_{1}, 0\right]+0.15 \max \left(b_{j}-\vartheta_{2}, 0\right)\right\} \quad \text { for } j=1,2,
\end{aligned}
$$

and the current-law OASI benefit function of each household is

$$
\operatorname{tr}_{S S, t}\left(i, b_{1}, b_{2}, m\right)= \begin{cases}\psi_{t} \max \left[\psi\left(i, b_{1}\right)+\psi\left(i, b_{2}\right), 1.5 \psi\left(i, b_{1}\right), 1.5 \psi\left(i, b_{2}\right)\right] & \text { if } m=0, \\ \psi_{t} \max \left[\psi\left(i, b_{1}\right), \psi\left(i, b_{2}\right)\right] & \text { if } m=1,2\end{cases}
$$

where $\psi_{t}$ is an OASI benefit adjustment factor. The adjustment factor is set at 1.0 in the baseline economy. When both the husband and the wife are alive $(m=0)$, the household's OASI benefit is $1.5 \psi\left(i, b_{1}\right)$ if $\psi\left(i, b_{2}\right)<0.5 \psi\left(i, b_{1}\right)$, it is $1.5 \psi\left(i, b_{2}\right)$ if $\psi\left(i, b_{1}\right)<0.5 \psi\left(i, b_{2}\right)$, and it is $\psi\left(i, b_{1}\right)+\psi\left(i, b_{2}\right)$ otherwise. When one of those is deceased ( $m=1,2)$, the OASI benefit is either $\psi\left(i, b_{1}\right)$ or $\psi\left(i, b_{2}\right)$, whichever is larger.

Decision Rules. Solving the household's problem for $c, h_{1}$, and $h_{2}$ for all possible states, the household's decision rules, $c\left(\mathbf{s}, \mathbf{S}_{t} ; \mathbf{\Psi}_{t}\right), h_{1}\left(\mathbf{s}, \mathbf{S}_{t} ; \mathbf{\Psi}_{t}\right)$, and $h_{2}\left(\mathbf{s}, \mathbf{S}_{t} ; \mathbf{\Psi}_{t}\right)$, are obtained numerically ${ }^{10}$ The other decision rules are also obtained as

$$
\begin{aligned}
a^{\prime}\left(\mathbf{s}, \mathbf{S}_{t} ; \mathbf{\Psi}_{t}\right)= & \frac{1}{1+\mu}\left[\left(1+r_{t}\right) a+w_{t} e_{1} h_{1}\left(\mathbf{s}, \mathbf{S}_{t} ; \mathbf{\Psi}_{t}\right)+w_{t} e_{2} h_{2}\left(\mathbf{s}, \mathbf{S}_{t} ; \mathbf{\Psi}_{t}\right)\right. \\
& -\tau_{I, t}\left(r_{t} a+w_{t} e_{1} h_{1}\left(\mathbf{s}, \mathbf{S}_{t} ; \mathbf{\Psi}_{t}\right)+w_{t} e_{2} h_{2}\left(\mathbf{s}, \mathbf{S}_{t} ; \mathbf{\Psi}_{t}\right) ; m, n_{m, i}\right) \\
& -\tau_{P, t}\left(w_{t} e_{1} h_{1}\left(\mathbf{s}, \mathbf{S}_{t} ; \mathbf{\Psi}_{t}\right), w_{t} e_{2} h_{2}\left(\mathbf{s}, \mathbf{S}_{t} ; \mathbf{\Psi}_{t}\right)\right)+t r_{S S, t}\left(i, b_{1}, b_{2}, m\right) \\
& \left.+\left(1+\mathbf{1}_{\{m=0\}}\right)\left(\operatorname{tr}_{L S, t}+\mathbf{1}_{\left\{i<I_{R}\right\}} q_{t}\right)-c\left(\mathbf{s}, \mathbf{S}_{t} ; \mathbf{\Psi}_{t}\right)\right] \geq a_{\min }^{\prime}(\mathbf{s}), \\
b_{1}^{\prime}\left(\mathbf{s}, \mathbf{S}_{t} ; \mathbf{\Psi}_{t}\right)= & \mathbf{1}_{\left\{i<I_{R}, m \neq 2\right\}} \frac{1}{i-20}\left[(i-21) b_{1}+\min \left(w_{t} e_{1} h_{1}\left(\mathbf{s}, \mathbf{S}_{t} ; \mathbf{\Psi}_{t}\right), \vartheta_{\max }\right)\right]+\mathbf{1}_{\left\{i \geq I_{R} \text { or } m=2\right\}} b_{1}, \\
b_{2}^{\prime}\left(\mathbf{s}, \mathbf{S}_{t} ; \mathbf{\Psi}_{t}\right)= & \mathbf{1}_{\left\{i<I_{R}, m \neq 1\right\}} \frac{1}{i-20}\left[(i-21) b_{2}+\min \left(w_{t} e_{2} h_{2}\left(\mathbf{s}, \mathbf{S}_{t} ; \mathbf{\Psi}_{t}\right), \vartheta_{\max }\right)\right]+\mathbf{1}_{\left\{i \geq I_{R} \text { or } m=1\right\}} b_{2} .
\end{aligned}
$$

The Distribution of Households. Let $x_{t}(\mathbf{s})$ be the growth-adjusted population density of households in period $t$, and let $X_{t}(\mathbf{s})$ be the corresponding cumulative distribution function. At age 21, a proportion $\eta$ of

\footnotetext{
${ }^{10}$ This paper discretizes the individual state space and solves the Kuhn-Tucker conditions of the household problem for each state by using a Newton-type nonlinear equation solver (a modified Powell hybrid algorithm). See the Appendix for the computational algorithm used to solve the problem.
} 
men and women are married and a proportion $1-\eta$ are single. For simplicity, households enter the economy with no assets and working histories, i.e., $a=b_{1}=b_{2}=0$. The growth-adjusted populations of 21 -year-old men and women are both normalized to unity. Thus, the populations of 21-year-old households are

$$
\begin{aligned}
& \int_{A \times B^{2} \times E^{2}} d X_{t}\left(21, a, b_{1}, b_{2}, e_{1}, e_{2}, m=0\right)=\int_{E^{2}} d X_{t}\left(21,0,0,0, e_{1}, e_{2}, 0\right)=\eta \\
& \int_{A \times B^{2} \times E^{2}} d X_{t}\left(21, a, b_{1}, b_{2}, e_{1}, e_{2}, m=1\right)=\int_{E} d X_{t}\left(21,0,0,0, e_{1}, 0,1\right)=1-\eta \\
& \int_{A \times B^{2} \times E^{2}} d X_{t}\left(21, a, b_{1}, b_{2}, e_{1}, e_{2}, m=2\right)=\int_{E} d X_{t}\left(21,0,0,0,0, e_{2}, 2\right)=1-\eta,
\end{aligned}
$$

and the total population of 21-year-old households is $2-\eta$. Let $\nu$ be the time-invariant population growth rate. The law of motion of the growth-adjusted population distribution is then

$$
\begin{aligned}
x_{t+1}\left(\mathbf{s}^{\prime}\right)=\frac{1}{1+\nu} \sum_{m=0}^{2} & \int_{A \times B^{2} \times E^{2}} \mathbf{1}_{\left\{a^{\prime}=a^{\prime}\left(\mathbf{s}, \mathbf{S}_{t} ; \boldsymbol{\Psi}_{t}\right), b_{1}^{\prime}=b_{1}^{\prime}\left(\mathbf{s}, \mathbf{S}_{t} ; \boldsymbol{\Psi}_{t}\right), b_{2}^{\prime}=b_{2}^{\prime}\left(\mathbf{s}, \mathbf{S}_{t} ; \boldsymbol{\Psi}_{t}\right)\right\}} \\
& \times \pi_{i}\left(e_{1}^{\prime}, e_{2}^{\prime}, m^{\prime} \mid e_{1}, e_{2}, m\right) d X_{t}(\mathbf{s}),
\end{aligned}
$$

where $\pi_{i}\left(e_{1}^{\prime}, e_{2}^{\prime}, m^{\prime} \mid e_{1}, e_{2}, m\right)$ is the transition probability density function of the exogenous state variables.

Aggregation. The growth-adjusted private wealth, $W_{P, t}$, the capital stock (national wealth), $K_{t}$, in a closed economy, and the labor supply in efficiency units, $L_{t}$, are

$$
\begin{aligned}
& W_{P, t}=\sum_{i=21}^{I} \sum_{m=0}^{2} \int_{A \times B^{2} \times E^{2}} a d X_{t}(\mathbf{s}), \\
& K_{t}=W_{P, t}+W_{G, t}, \\
& L_{t}=\sum_{i=21}^{I_{R}-1} \sum_{m=0}^{2} \int_{A \times B^{2} \times E^{2}}\left(e_{1} h_{1}\left(\mathbf{s}, \mathbf{S}_{t} ; \mathbf{\Psi}_{t}\right)+e_{2} h_{2}\left(\mathbf{s}, \mathbf{S}_{t} ; \mathbf{\Psi}_{t}\right)\right) d X_{t}(\mathbf{s}) .
\end{aligned}
$$

\subsection{The Firm}

In each period, the representative firm chooses the capital input, $\tilde{K}_{t}$, and efficiency labor input, $\tilde{L}_{t}$, to maximize its profit, taking factor prices, $r_{t}$ and $w_{t}$, as given, i.e.,

(9) $\max _{\tilde{K}_{t}, \tilde{L}_{t}} F\left(\tilde{K}_{t}, \tilde{L}_{t}\right)-\left(r_{t}+\delta\right) \tilde{K}_{t}-w_{t} \tilde{L}_{t}$, 
where $F(\cdot)$ is a constant-returns-to-scale production function,

$$
F\left(\tilde{K}_{t}, \tilde{L}_{t}\right)=A \tilde{K}_{t}^{\theta} \tilde{L}_{t}^{1-\theta}
$$

with the growth-adjusted total factor productivity $A$, and $\delta$ is the depreciation rate of capital. The profit maximizing conditions are

$$
F_{K}\left(\tilde{K}_{t}, \tilde{L}_{t}\right)=r_{t}+\delta, \quad F_{L}\left(\tilde{K}_{t}, \tilde{L}_{t}\right)=w_{t}
$$

and the factor markets are cleared when $K_{t}=\tilde{K}_{t}$ and $L_{t}=\tilde{L}_{t}$.

\subsection{The Government}

In the model economy, the payroll tax rate is fixed at the same level, and the benefits are adjusted proportionately so that the social security budget is always balanced ${ }^{11}$ The government's OASI payroll tax revenue, $T_{P, t}$, is

$$
T_{P, t}\left(\bar{\tau}_{P, t}\right)=\sum_{i=21}^{I_{R}-1} \sum_{m=0}^{2} \int_{A \times B^{2} \times E^{2}} \tau_{P, t}\left(w_{t} e_{1} h_{1}\left(\mathbf{s}, \mathbf{S}_{t} ; \boldsymbol{\Psi}_{t}\right), w_{t} e_{2} h_{2}\left(\mathbf{s}, \mathbf{S}_{t} ; \boldsymbol{\Psi}_{t}\right) ; \bar{\tau}_{P, t}\right) d X_{t}(\mathbf{s})
$$

and the OASI benefit expenditure, $T R_{S S, t}$, is

$$
T R_{S S, t}\left(\psi_{t}\right)=\sum_{i=I_{R}}^{I} \sum_{m=0}^{2} \int_{A \times B^{2} \times E^{2}} \operatorname{tr}_{S S, t}\left(i, b_{1}, b_{2}, m ; \psi_{t}\right) d X_{t}(\mathbf{s}) .
$$

In the baseline economy, the parameter, $\psi_{t}$, of the benefit function set at 1.0 and the OASI residual is calculated as $T R_{O}=T_{P, t}\left(\bar{\tau}_{P, t}\right)-T R_{S S, t}\left(\psi_{t}\right)$. The OASI residual includes the OASI benefits not considered in this model economy and the administrative costs. In the policy experiments below, $\bar{\tau}_{P, t}$ and $T R_{O}$ are kept at the baseline levels, and the benefit parameter, $\psi_{t}$, is adjusted so that the OASI budget is balanced, i.e., $T R_{S S, t}\left(\psi_{t}\right)=T_{P, t}\left(\bar{\tau}_{P, t}\right)-T R_{O}$

\footnotetext{
${ }^{11}$ If a policy change increases the labor income of working-age households, then all other things being equal, the elderly households will also be better off through the increased social security benefit under this assumption.
} 
The government's income tax revenue is

(13)

$$
T_{I, t}\left(\varphi_{t}\right)=\sum_{i=21}^{I} \sum_{m=0}^{2} \int_{A \times B^{2} \times E^{2}} \tau_{I, t}\left(r_{t} a+w_{t} e_{1} h_{1}\left(\mathbf{s}, \mathbf{S}_{t} ; \mathbf{\Psi}_{t}\right)+w_{t} e_{2} h_{2}\left(\mathbf{s}, \mathbf{S}_{t} ; \mathbf{\Psi}_{t}\right) ; m, n_{m, i}, \varphi_{t}\right) d X_{t}(\mathbf{s})
$$

and the aggregate lump-sum transfer expenditure is

$$
T R_{L S, t}\left(\operatorname{tr}_{L S, t}\right)=\sum_{i=21}^{I} \sum_{m=0}^{2} \int_{A \times B^{2} \times E^{2}}\left(1+\mathbf{1}_{\{m=0\}}\right) \operatorname{tr}_{L S, t} d X_{t}(\mathbf{s})
$$

The government collects accidental bequests—remaining wealth held by deceased households—at the end of period $t$ and uniformly distributes the bequests to all working-age adults in the same period 12 The revenue from the accidental bequests is

$$
Q_{t}=\sum_{i=21}^{I} \sum_{m=0}^{2} \int_{A \times B^{2} \times E^{2}}\left(1-\phi_{m, i}\right)(1+\mu) a^{\prime}\left(\mathbf{s}, \mathbf{S}_{t} ; \mathbf{\Psi}_{t}\right) d X_{t}(\mathbf{s})
$$

where the survival rate of married couple $(m=0)$ is calculated as $\phi_{0, i}=1-\left(1-\phi_{1, i}\right)\left(1-\phi_{2, i}\right)$. The accidental bequests per working-age adult is

$$
q_{t}=\left(\sum_{i=21}^{I_{R}-1} \sum_{m=0}^{2} \int_{A \times B^{2} \times E^{2}}\left(1+\mathbf{1}_{\{m=0\}}\right) d X_{t}(\mathbf{s})\right)^{-1} Q_{t}
$$

The law of motion of government net worth is

$$
W_{G, t+1}=\frac{1}{(1+\mu)(1+\nu)}\left[\left(1+r_{t}\right) W_{G, t}+T_{I, t}\left(\varphi_{t}\right)-C_{G, t}-T R_{L S, t}\left(\operatorname{tr}_{L S, t}\right)\right]
$$

Note that the aggregate variables are normalized by the long-run productivity growth rate, $1+\mu$, and the population growth rate, $1+\nu$, so that the balanced growth path of the economy is obtained as a steady-state equilibrium.

\subsection{Recursive Competitive Equilibrium}

The recursive competitive equilibrium of this model economy is defined as follows.

\footnotetext{
${ }^{12}$ Since there are no aggregate shocks in the model economy, the government can perfectly predict the sum of accidental bequests during the period.
} 
Definition Recursive Competitive Equilibrium: Let $\mathbf{s}=\left(i, a, b_{1}, b_{2}, e_{1}, e_{2}, m\right)$ be the individual state of the households, let $\mathbf{S}_{t}=\left(x(\mathbf{s}), W_{G, t}\right)$ be the state of the economy, and let $\boldsymbol{\Psi}_{t}$ be the government policy schedule known at the beginning of period $t$,

$$
\mathbf{\Psi}_{t}=\left\{C_{G, s}, \operatorname{tr}_{L S, s}, \tau_{I, s}(\cdot), \tau_{P, s}(\cdot), \operatorname{tr}_{S S, s}(\cdot), W_{G, s+1}, q_{s}\right\}_{s=t}^{\infty}
$$

A time series of factor prices and the government policy variables,

$$
\boldsymbol{\Omega}_{t}=\left\{r_{s}, w_{s}, C_{G, s}, \operatorname{tr}_{L S, s}, \varphi_{s}, \bar{\tau}_{P, s}, \psi_{s}, W_{G, s}, q_{s}\right\}_{s=t}^{\infty},
$$

where $\varphi_{t}$ is a parameter of the individual income tax function, $\bar{\tau}_{P, t}$ is a parameter of the payroll tax function, and $\psi_{t}$ is a parameter of the Social Security benefit function; the value functions of households, $\left\{v\left(\mathbf{s}, \mathbf{S}_{s} ; \mathbf{\Psi}_{s}\right)\right\}_{s=t}^{\infty}$, the decision rules of households,

$$
\left\{c\left(\mathbf{s}, \mathbf{S}_{s} ; \boldsymbol{\Psi}_{s}\right), h_{1}\left(\mathbf{s}, \mathbf{S}_{s} ; \boldsymbol{\Psi}_{s}\right), h_{2}\left(\mathbf{s}, \mathbf{S}_{s} ; \boldsymbol{\Psi}_{s}\right), a^{\prime}\left(\mathbf{s}, \mathbf{S}_{s} ; \boldsymbol{\Psi}_{s}\right), b_{1}^{\prime}\left(\mathbf{s}, \mathbf{S}_{s} ; \boldsymbol{\Psi}_{s}\right), b_{2}^{\prime}\left(\mathbf{s}, \mathbf{S}_{s} ; \boldsymbol{\Psi}_{s}\right)\right\}_{s=t}^{\infty},
$$

and the distribution of households, $\left\{x_{s}(\mathbf{s})\right\}_{s=t}^{\infty}$, are in a recursive competitive equilibrium if, for all $s=$ $t, \ldots, \infty$, (i) each household solves the optimization problem (1)-(8), taking $\mathbf{S}_{s}$ and $\mathbf{\Psi}_{s}$ as given; (ii) the firm solves its profit maximization problem (9)-(10); (iii) the government policy schedule is satisfied (11)177; and (iv) the goods and factor markets are cleared. The economy is in a steady-state equilibrium and on a balanced growth path if, in addition, $\mathbf{S}_{s}=\mathbf{S}_{s+1}$ and $\boldsymbol{\Psi}_{s+1}=\boldsymbol{\Psi}_{s}$ for all $s=t, \ldots, \infty$.

\section{Calibration}

The model is calibrated to the 2013 U.S. economy with the current-law Social Security system that includes the spousal and survivors benefits. The baseline economy is assumed to be in a steady-state (stationary) equilibrium and on a balanced-growth path. Table 1 shows the target variables and values in the baseline economy, and Table 2 shows the main parameter values and the baseline government policy values. The discount factor, $\beta$, of households is set at 0.9804 so that the capital-output ratio, $K_{t} / Y_{t}$, is 2.8 in the baseline economy. The depreciation rate of the capital stock, $\delta$, is set at $7.5 \%$ so that the interest rate, $r_{t}$, is $5.0 \%$ in the baseline economy. The growth-adjusted total factor productivity, $A$, of the production function 
Table 1: Target variables and values in the baseline economy

\begin{tabular}{llll}
\hline \hline $\begin{array}{l}\text { Target variables } \\
\text { (Just-identifying restrictions) }\end{array}$ & $\begin{array}{l}\text { Target } \\
\text { values }\end{array}$ & $\begin{array}{l}\text { Baseline } \\
\text { values }\end{array}$ & Determined mainly by \\
\hline Capital-output ratio $K_{t} / Y_{t}$ & 2.80 & 2.80 & Discount factor $\beta$ \\
Interest rate $r_{t}$ & 0.05 & 0.05 & Depreciation rate $\delta$ \\
Wage rate $w_{t}$ & 1.00 & 1.00 & Total factor productivity $A$ \\
Income tax revenue / output $T_{I, t} / Y_{t}$ & 0.10 & 0.10 & Tax parameter $\varphi_{t}$ \\
Frisch elasticity of working hours (average worker) & 0.50 & 0.50 & Consumption share parameter $\alpha$ \\
Labor force participation rate: men (ages 25-54) & 0.887 & 0.887 & Utility parameter $\kappa_{1}$ \\
Labor force participation rate: women (ages 25-54) & 0.745 & 0.745 & Utility parameter per newborn $\kappa_{2}$ \\
Female work hours / male work hours (all workers) & 0.895 & 0.895 & Time cost per newborn $\kappa$ \\
\hline \hline
\end{tabular}

\begin{tabular}{|c|c|c|c|}
\hline $\begin{array}{l}\text { Target variables } \\
\text { (Overidentifying restrictions) }\end{array}$ & $\begin{array}{l}\text { Target } \\
\text { values }\end{array}$ & $\begin{array}{l}\text { Baseline } \\
\text { values }\end{array}$ & Determined mainly by \\
\hline $\begin{array}{r}\text { OASI benefit share: workers benefits } \\
\text { : spousal benefits } \\
\text { : survivors benefits }\end{array}$ & $\begin{array}{l}80.1-81.2 \% \\
4.1-4.3 \% \\
14.7-15.6 \%\end{array}$ & $\begin{array}{l}80.5 \% \\
3.9 \% \\
15.6 \%\end{array}$ & Auto correlation parameter of log wage $\rho$ \\
\hline Variance of log labor income by age & $0.40-1.00$ & $0.46-0.96$ & Standard deviation of log wage shocks $\sigma$ \\
\hline
\end{tabular}

is set at 0.9228 to normalize the wage rate, $w_{t}$, to unity. The limit of the effective marginal income tax rate, $\varphi_{t}$, is set at $33.6 \%$ so that the government's income tax revenue is $10.0 \%$ of the total output in the baseline economy.

The share parameter of consumption, $\alpha$, in the utility function is set at 0.6563 so that the Frisch elasticity of the average worker (the worker with the average work hours) is 0.5 . The parameters of utility from staying at home, $\kappa_{1}$ and $\kappa_{2}$, are set at 0.4427 and 1.6928, respectively, so that the labor force participation rates of men and women ages $25-54$ are $88.7 \%$ and $74.5 \%$, respectively. The parameter of time cost for childbirth and childcare, $\kappa$, is chosen to be 1.1812 so that the average work hours of female workers is $89.5 \%$ of the average male work hours. The autocorrelation parameter, $\rho$, of log wage (earning ability) is set at 0.87 , and the standard deviation of log wage shocks is set at 0.39 , so that

- the variance of the household's log labor income by age in the baseline economy is consistent with the recent survey data (the 2010 Survey of Consumer Finances);

- the shares of old-age retirement benefits, spousal benefits, and survivors benefits in total OASI benefits are close to the recent Social Security statistics (Social Security Administration, 2014).

The autocorrelation parameter and the standard deviation concurrently determine both the labor income 
Table 2: Main parameter values and baseline government policy values

\begin{tabular}{|c|c|c|c|}
\hline$\underline{\text { Parameters }}$ & & Values & Comments / Targets \\
\hline $\begin{array}{l}\text { Maximum possible age } \\
\text { Retirement age } \\
\text { Share of married people at age } 21 \\
\text { Productivity growth rate } \\
\text { Population growth rate }\end{array}$ & $\begin{array}{c}I \\
I_{R} \\
\eta \\
\mu \\
\nu\end{array}$ & $\begin{array}{l}100 \\
66 \\
0.75 \\
0.018 \\
0.010\end{array}$ & $\begin{array}{l}\text { Current full retirement age } \\
\text { Share of married households } 0.60^{b} \\
\text { Average rate in 1981-2013 } \\
\text { Average rate in 1981-2013 }\end{array}$ \\
\hline $\begin{array}{l}\text { Discount factor } \\
\text { Growth-adjusted discount factor } \\
\text { Share parameter of consumption } \\
\text { Coefficient of relative risk aversion } \\
\text { Adjustment parameter of consumption } \\
\text { Utility from staying at home (common) } \\
\text { Utility from staying at home (childbirth/care) } \\
\text { Time cost parameter for women } \\
\text { Autocorrelation parameter of log wage } \\
\text { Standard deviation of log wage shocks } \\
\text { Average median wage: men aged } 21-65 \\
\text { Intrafamily wage correlation }\end{array}$ & $\begin{array}{c}\beta \\
\tilde{\beta} \\
\alpha \\
\gamma \\
\lambda \\
\kappa_{1} \\
\kappa_{2} \\
\kappa \\
\rho \\
\sigma \\
\bar{e}_{1} \\
\omega\end{array}$ & $\begin{array}{l}0.9804 \\
0.9690 \\
0.6563 \\
2.0 \\
0.6 \\
0.4427 \\
1.6928 \\
1.1812 \\
0.87 \\
0.390 \\
1.0 \\
0.25\end{array}$ & $\begin{array}{l}K_{t} / Y_{t}=2.8 \text { in the baseline } \\
\tilde{\beta}=\beta(1+\mu)^{\alpha(1-\gamma)} \\
\text { Frisch elasticity } 0.5 \\
\text { Bernheim et al. (2008) } \\
\text { Male (ages } 25-54) \text { participation rate } 88.7 \% \\
\text { Female (ages } 25-54 \text { ) participation rate } 74.5 \% \\
\text { Female-male working hour ratio } 0.895 \\
\text { Shares of spousal and survivors benefits } \\
\text { Survey of Consumer Finances (2010) } \\
\text { Hyslop (2001) with adjustment }\end{array}$ \\
\hline $\begin{array}{l}\text { Share parameter of capital stock } \\
\text { Depreciation rate of capital stock } \\
\text { Total factor productivity } \\
\end{array}$ & $\begin{array}{l}\theta \\
\delta \\
A\end{array}$ & $\begin{array}{l}0.35 \\
0.0750 \\
0.9228 \\
\end{array}$ & $\begin{array}{l}\text { NIPA data } \\
r=0.050 \text { in the baseline } \\
w=1.0 \text { in the baseline }\end{array}$ \\
\hline $\begin{array}{c}\text { Income tax parameters: tax rate limit } \\
\text { married }(m=0): \text { curvature } \\
\quad: \text { scale } \\
\text { single }(m=1,2): \text { curvature } \\
\quad: \text { scale } \\
\text { Standard deduction per person } \\
\text { Exemption per family member }\end{array}$ & $\begin{array}{c}\varphi_{t} \\
\varphi_{m, 1} \\
\varphi_{m, 2} \\
\varphi_{m, 1} \\
\varphi_{m, 2} \\
\xi_{1} \\
\xi_{2}\end{array}$ & $\begin{array}{l}0.3360 \\
0.8564 \\
0.3604 \\
0.6785 \\
0.4575 \\
0.0977 \\
0.0624 \\
\end{array}$ & $\begin{array}{l}T_{I, t} / Y_{t}=0.10 \text { in the baseline } \\
\} \text { Estimated by OLS }\end{array}$ \\
\hline $\begin{array}{l}\text { Social Security payroll tax rate } \\
\text { Maximum taxable earnings } \\
\text { Replacement rate threshold: } 0.90 \& 0.32 \\
: 0.32 \& 0.15\end{array}$ & $\begin{array}{c}\bar{\tau}_{P, t} \\
\vartheta_{\max } \\
\vartheta_{1} \\
\vartheta_{2}\end{array}$ & $\begin{array}{l}0.1007 \\
1.8203 \\
0.1520 \\
0.9160 \\
\end{array}$ & $\begin{array}{l}\text { Effective OASI tax rate } 0.106 / 1.053 \\
\$ 113,700 \text { in } 2013 \\
\$ 791 \times 12=\$ 9,492 \text { in } 2013 \\
\$ 4,768 \times 12=\$ 57,216 \text { in } 2013\end{array}$ \\
\hline $\begin{array}{l}\text { Government consumption } \\
\text { Lump-sum transfers per person } \\
\text { OASI benefit adjustment factor } \\
\text { OASI residual } \\
\text { Government net worth } \\
\text { Accidental bequests per working-age adult }\end{array}$ & $\begin{array}{c}C_{G, t} \\
\operatorname{tr}_{L S, t} \\
\psi_{t} \\
T R_{O} \\
W_{G, t} \\
q_{t} \\
\end{array}$ & $\begin{array}{l}8.2962 \\
0.0 \\
1.0 \\
0.2456 \\
15.8985 \\
0.0209 \\
\end{array}$ & $\begin{array}{l}T R_{O}=T_{P, t}-T R_{S S, t} \\
W_{G, t} / Y_{t}=0.20 \text { in the baseline }\end{array}$ \\
\hline
\end{tabular}

${ }^{a}$ When the population of age-21 men and women are both normalized to unity, working age population (aged 21-66) is 70.13, and retired population (aged 66-100) is 17.99 in the model economy. ${ }^{b}$ When $\eta$ is 0.75 , the number of working-age households is 44.80 , and the number of retired households is $13.76 .{ }^{c}$ One model unit is equal to $\$ 62,461$ in 2013 growth-adjusted dollars. 
inequality of each age and the lifetime labor income inequality, and the latter mainly affects the shares of spousal and survivors benefits in total OASI benefits.

\subsection{Demographics}

Households are assumed to enter the economy beginning at age 21 and possibly live up to age 100 $(I=100)$. For simplicity, all households are assumed to start receiving their Social Security benefits when the members turn age $66\left(I_{R}=66\right)$, which is the current full retirement age for workers born in 194354. From the estimates by the Social Security Administration (SSA), the average population growth rate is calculated as $0.96 \%$ in 1980-2013. The population growth rate, $\nu$, in the model economy is set at $1.0 \%$. The conditional survival rates of men and women at the end of each year of age, $\phi_{1, i}$ and $\phi_{2, i}$, are calculated from Table 4.C6 2009 Period Life Table in SSA (2014). The survival rates at the end of age 100 are replaced with zero. For simplicity, households are assumed to be either married or single households at age 21, and the model abstracts from possible marriages and divorces. Thus, the transition matrix of the marital status, $\Pi_{m, i}=\left[p\left(m^{\prime} \mid m\right)\right]$ for $i<I-1$, is solely determined by the survival rates as

$$
\Pi_{m, i}=\left(\begin{array}{ccc}
\phi_{1, i} \phi_{2, i} & \phi_{1, i}\left(1-\phi_{2, i}\right) & \left(1-\phi_{1, i}\right) \phi_{2, i} \\
0 & \phi_{1, i} & 0 \\
0 & 0 & \phi_{2, i}
\end{array}\right) .
$$

To avoid introducing an additional heterogeneity of households to the model economy, the numbers of newborn babies, $n_{m, i}$, in a married household and a single female household are assumed to be uniform and only dependent on the marital status ( $m=0$ or 2 ) and age of the household. The average number of newborn babies by age in a household is calculated from the age-specific fertility rates for 2006 in United Nations (2008). The fertility rates of 5-year age groups of women (ages 15-19, 20-24, ., 45-49) are smoothed out by linear regression. Figure 1 shows the average number of newborn babies assumed in the model economy.

\subsection{Household Preferences}

The coefficient of relative risk aversion, $\gamma$, for the combination of consumption and leisure is set at 2.0, which is within the range of numbers assumed in macroeconomic and public finance literature 13 The share

\footnotetext{
${ }^{13}$ For example, Domeij and Heathcote (2004) use 1.0, İmrohoroğlu, İmrohoroğlu, and Joines (1995) use 2.0, and Auerbach and Kotlikoff (1987) and Conesa, Kitao, and Krueger (2009) use 4.0.
} 
Figure 1: The Average Number of Newborn Babies by Age

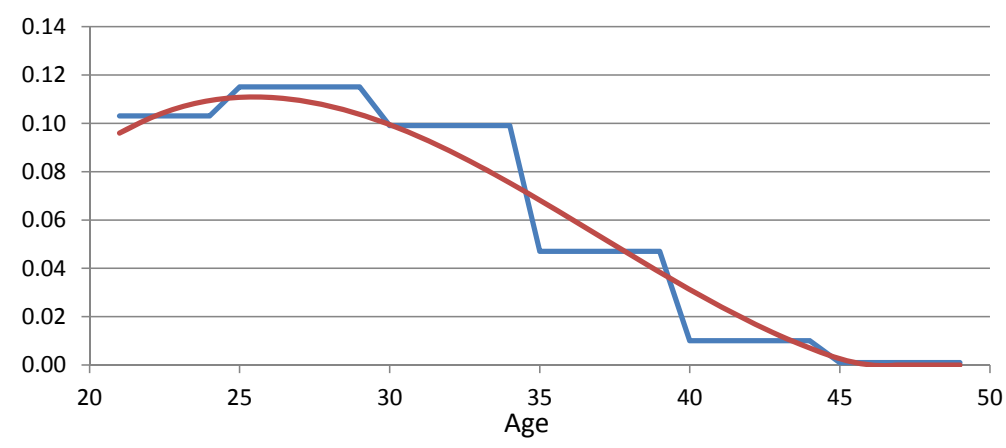

—Age-specific fertility rate -Avg. number of newborns (OLS)

parameter of consumption in the utility function, $\alpha$, is set at 0.6563 so that the Frisch elasticity of working hours for the average worker (the worker with the average working hours, $\bar{h}$ ) is 0.5 . In this paper, the Frisch elasticity is calculated as

$$
\frac{1-\bar{h}}{\bar{h}} \frac{1-\alpha(1-\gamma)}{\gamma}=0.5
$$

where $\bar{h}=0.6235$ in the baseline economy.

With these parameter values of $\alpha$ and $\gamma$, the coefficient of relative risk aversion for consumption is calculated as

$$
-\frac{c u_{c c}(c, l)}{u_{c}(c, l)}=1-\alpha(1-\gamma)=1-0.6563(1-2.0)=1.6563
$$

The elasticity of inter-temporal substitution of working hours is approximately equal to

$$
\begin{aligned}
\frac{d \ln \left(h_{t+1} / h_{t}\right)}{d \ln \left(\tilde{w}_{t+1} / \tilde{w}_{t}\right)} & \approx-\frac{1-\bar{h}}{\bar{h}} \frac{d \ln \left(l_{t+1} / l_{t}\right)}{d \ln \left(\tilde{w}_{t+1} / \tilde{w}_{t}\right)}=\frac{1-\bar{h}}{\bar{h}} \frac{1}{1-(1-\alpha)(1-\gamma)} \\
& =\frac{1-0.6235}{0.6235} \frac{1}{1-(1-0.6563)(1-2.0)}=0.4494,
\end{aligned}
$$

where $\tilde{w}_{t}$ is the after-tax wage rate of the household. The elasticity of substitution of the husband's market work hours for the wife's hours is also approximately 0.4494 . The consumption adjustment factor for a married couple, $\lambda$ is assumed to be 0.6, following Bernheim, Forni, Gokhale, and Kotlikoff (2003) ${ }^{14}$

\footnotetext{
${ }^{14}$ Attanasio, Low, and Sánchez-Marcos (2008) use the parameter value corresponding to $\lambda=0.67$. The difference between 0.6 and 0.67 is almost negligible in the policy experiments.
} 
According to Table 3 of Bureau of Labor Statistics (2013a), the labor force participation rates of men and women ages 25-54 in 2012 are $88.7 \%$ and $74.5 \%$, respectively. The parameters of utility from staying at home, $\kappa_{1}$ and $\kappa_{2}$, are set at 0.4427 and 1.6928, respectively, so that the labor force participation rates of men and women are matched to the data. Using Table 5 of Bureau of Labor Statistics (2013b), the average weekly working hours of female workers is calculated as 36.7 in 2012, which is $89.5 \%$ of the average male working hours, 41.0. The parameter of time cost for childbirth and childcare, $\kappa$, is set at 1.1812 per newborn baby so that the average work hours of female workers (ages 21-65) is $89.5 \%$ of the average male work hours.

The discount factor of households, $\beta$, is set at 0.9804 so that the capital-output ratio, $K_{t} / Y_{t}$, is equal to 2.8 in the baseline economy. According to the national income and product accounts (NIPA) and fixed assets accounts (FAA), the capital-output ratio in the United States, defined by the ratio of the fixed assets to GDP, is on average 2.99 in 2007-2013. According to International Investment Position Tables (IIP), net international investment position is on average -0.196 as a share of GDP in the same period. So, the capitaloutput ratio, defined by the ratio of the fixed assets owned by the U.S. residents to GDP, is lowered to 2.8 in the model economy. For simplicity, the present paper assumes a closed economy and the capital stock to be equal to national wealth. The ratio of government fixed assets to GDP is on average 0.73 , and the debt held by the public is on average 51\% of GDP, in 2007-2013. Thus, the ratio of government net worth to output, $W_{G, t} / Y_{t}$, is set to be 0.2 , and the ratio of private wealth to output, $W_{P, t} / Y_{t}$, is 2.6 in the baseline economy.

\subsection{Production Technology}

The share parameter of capital, $\theta$, is set at 0.35 , which is roughly consistent with the NIPA data 15 The depreciation rate of the capital stock, $\delta$, is chosen so that the interest rate, $r_{t}$, is $5.0 \%$, and the total factor productivity scalar, $A$, is adjusted so that the average wage rate, $w_{t}$, is normalized to 1.0 in the baseline economy. When the capital-output ratio, $K_{t} / Y_{t}$, is 2.8 , the Cobb-Douglas production function implies

$$
\begin{aligned}
& r_{t}+\delta=\frac{\theta Y_{t}}{K_{t}}=\frac{0.35}{2.8}=0.125 \quad \Longrightarrow \quad \delta=0.125-r_{t}=0.125-0.05=0.075 \\
& w_{t}=A(1-\theta)\left(\frac{K_{t}}{L_{t}}\right)^{\theta}=A(1-\theta)^{1-\theta}\left(\frac{K_{t}}{Y_{t}}\right)^{\theta}=0.65^{0.65} 2.8^{0.35} A=1.0 \quad \Longrightarrow \quad A=0.9228 .
\end{aligned}
$$

\footnotetext{
${ }^{15}$ In 2007-2013, labor income is on average 59.3\% of GDP, capital income (including depreciations) is $34.2 \%$ of GDP, and taxes on production and imports less subsidies are the remainder.
} 
According to the NIPA data, the average growth rate of real GDP per capita (in chained 2009 dollars) is $1.76 \%$ between 1981 and 2013. The labor-augmenting productivity growth rate, $\mu$, is set at $1.8 \%$ in the model economy. The growth-adjusted time discount factor is thus calculated as

$$
\tilde{\beta}=\beta(1+\mu)^{\alpha(1-\gamma)}=0.9804(1+0.018)^{0.6563(1-2.0)}=0.9690 .
$$

\subsection{Earning Ability Processes}

The individual earning ability processes of men and women, $e_{1, i}$ and $e_{2, i}$, of age $i=21, \ldots, 65$ in the model economy are assumed to be

$$
\ln e_{j, i}=\ln \bar{e}_{j, i}+\ln z_{j, i}
$$

for $j=1$ and 2, where $\bar{e}_{j, i}$ is the median wage rate of men or women at age $i$. The persistent shock, $z_{j, i}$, follows an $\mathrm{AR}(1)$ process,

$$
\ln z_{j, i}=\rho \ln z_{j, i-1}+\epsilon_{j, i}
$$

for $i=22, \ldots, 65$, where $\epsilon_{j, i} \sim N\left(0, \sigma^{2}\right)$. The auto-correlation parameter, $\rho$, is assumed to be 0.87 , and the standard deviation, $\sigma$, is set at 0.39 for all $i$ and $j$. The $\log$ deviation from the mean, $\ln z_{i}$, is normally distributed and the variance is increasing in age. The variance of the age-21 log working ability, $\ln z_{j, 21}$, is set as

$$
V\left(\ln z_{j, 21}\right)=0.4 \lim _{i \rightarrow \infty} V\left(\ln z_{j, i}\right)=\frac{0.4}{1-\rho^{2}} \sigma^{2}=\frac{0.4}{1-0.87^{2}} 0.39^{2}=0.2503
$$

and the variance of $\ln z_{j, i}$ is calculated as

$$
V\left(\ln z_{j, i+1}\right)=\rho^{2} V\left(\ln z_{j, i}\right)+\sigma^{2}
$$

for $i=22, \ldots, 65$, so that the variance of log labor income by age is close to those calculated from the household wage income data in the 2010 Survey of Consumer Finances (SCF). The coefficient $0.4<1$ is chosen so that the variance of log earnings increases with the household's age. Figure 2 shows that the 
Figure 2: The Variance of Log Labor Income by Age

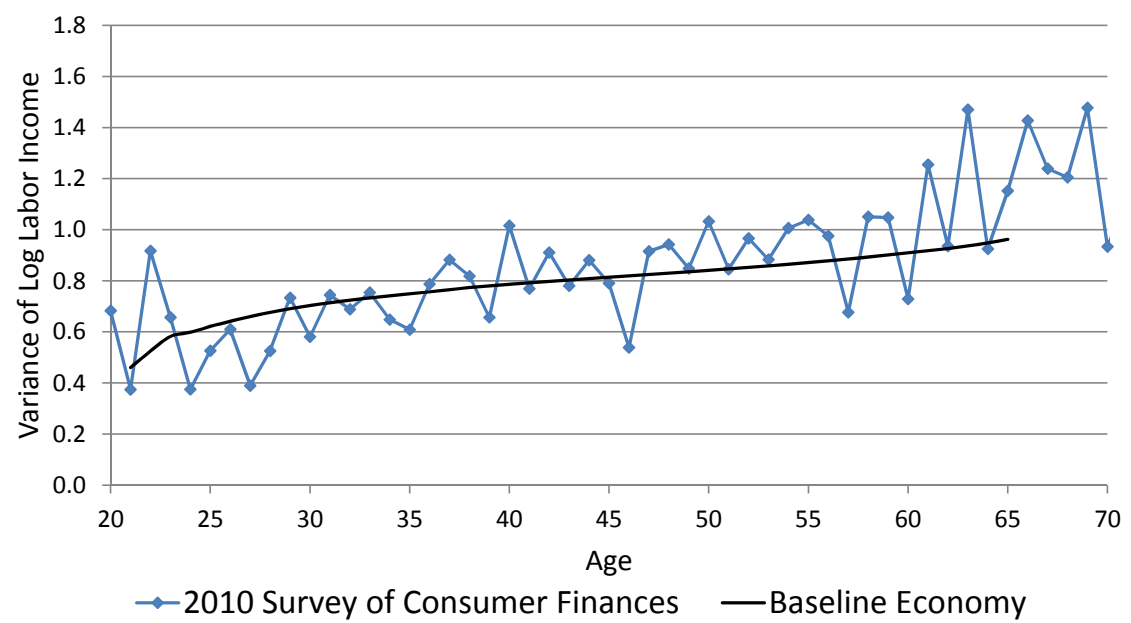

Sources: Author' calculations and the 2010 Survey of Consumer Finances (FRB, 2012).

variances of log labor income calculated using the 2010 SCF data (FRB, 2012) and those in the baseline economy are similar.

The median wage rates (earning abilities) of men and women ages $21-65, \bar{e}_{1, i}$ and $\bar{e}_{2, i}$, are constructed by using the 2011 median earnings of workers by sex and age in Table 4.B6 in Social Security Administration (2014). Because the median earnings are not shown for all ages in the table, the numbers are interpolated by using OLS for ages 21-70. Under this assumption, the average median earnings of women ages 21-65 is $70.2 \%$ of that of men of the same age group. In 2012, the median earnings of full-time female workers ages $21-65$ is $80.4 \%$ of that of full-time male workers of the same age group, according to Bureau of Labor Statistics (2013b). To convert the earnings profile to the full-time equivalent wage profile, the female earnings are multiplied by $80.5 / 70.2$. Figure 3 shows the original median earnings and the estimated earning ability profiles. The median wage rates are then normalized so that the population-weighted average of male median wages for ages $21-65$ is 1.0 . Under this normalization, the weighted average of female median wages is 0.804 .

In the baseline economy, the average labor income of all working-age households is 1.1534 . The average labor income of working-age households (ages 21-65) is $\$ 63,754$ in the 2010 SCF (FRB, 2012). Because labor income per capita increased about 13\% between 2010 and 2013, the average household labor income is estimated as $\$ 72,042$ in 2013 . Thus, in the baseline economy, one model unit is approximately equal to $\$ 72,042 / 1.1534=\$ 62,461$ in 2013 growth-adjusted dollars. 
Figure 3: The Earnings Profile of Men and Women (Median earnings of workers, by sex and age, 2011)

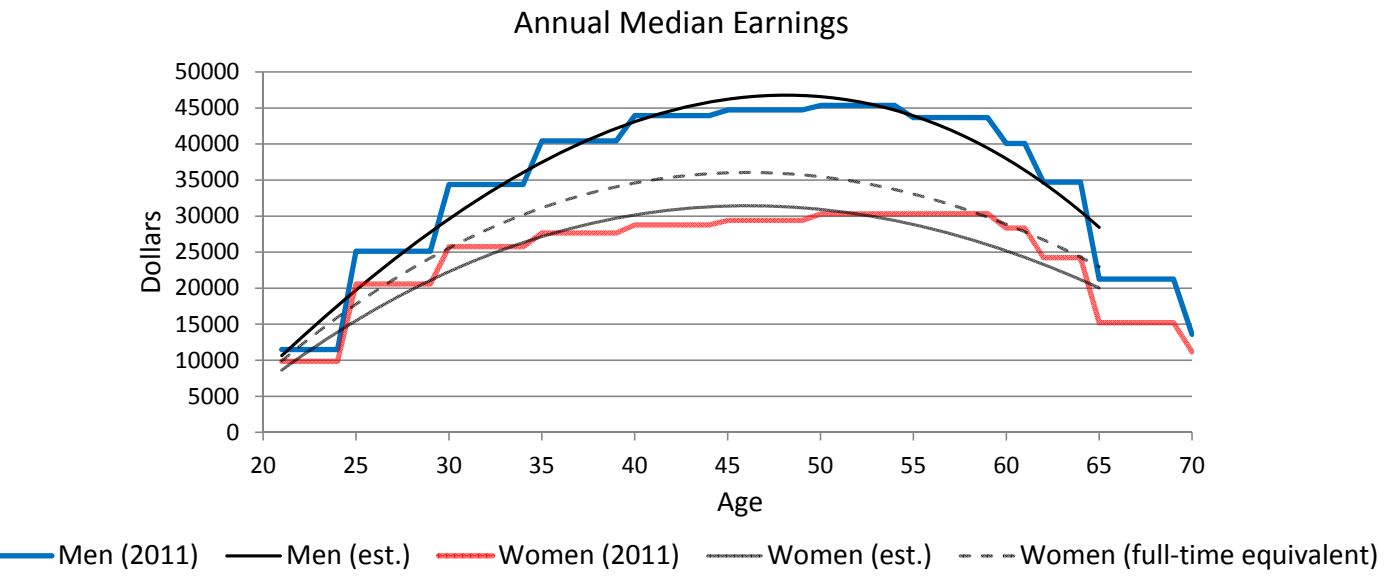

Sources: Author' calculations and Table 4.B6 in Social Secrurity Administration (2014).

As mentioned above, the autocorrelation parameter, $\rho$, is assumed to be 0.87 , and the standard deviation, $\sigma$, of the transitory shock is set at 0.39 . The $\log$ persistent shock, $\ln z_{j, i}$, is first discretized into 11 levels each by using the Gauss-Hermite quadrature nodes, and 5 levels of $\ln z_{j, i}$ are then generated by combining 4 nodes in each tail distribution into one node. The unconditional probability distribution of single households is $\pi_{e_{1}, i}=\pi_{e_{2}, i}=(0.0731,0.2422,0.3694,0.2422,0.0731)^{\prime}$ for $i=21, \ldots, 65$. The tail nodes are combined because matching the tail distributions of the wage rate is less important in this paper. The Markov transition matrix for single households, $\Pi_{e_{1}, i}=\left[\pi\left(e_{1, i+1}^{j^{\prime}} \mid e_{1, i}^{j}\right)\right]$ and $\Pi_{e_{2}, i}=\left[\pi\left(e_{2, i+1}^{k^{\prime}} \mid e_{2, i}^{k}\right)\right]$ for $i=21, \ldots, 64$, that corresponds to $\rho=0.87$ is calculated by using the bivariate normal distribution function as

$$
\Pi_{e_{1}, i}=\Pi_{e_{2}, i}=\left(\begin{array}{ccccc}
0.7337 & 0.2652 & 0.0011 & 0.0000 & 0.0000 \\
0.0800 & 0.7126 & 0.2068 & 0.0006 & 0.0000 \\
0.0002 & 0.1356 & 0.7283 & 0.1356 & 0.0002 \\
0.0000 & 0.0006 & 0.2068 & 0.7126 & 0.0800 \\
0.0000 & 0.0000 & 0.0011 & 0.2652 & 0.7337
\end{array}\right) .
$$

The earning ability processes of the husband and wife in a married household are assumed to be correlated. Suppose that, in each period, the wage rates of the husband and wife are perfectly correlated with probability $\omega$ and uncorrelated with probability $1-\omega$. Then, the unconditional probability distribution of 
married households is obtained as

$$
\pi_{\left(e_{1}, e_{2}\right), i}=\omega \operatorname{diag}\left(\pi_{e_{1}, i}\right)+(1-\omega)\left(\pi_{e_{1}, i}\right)\left(\pi_{e_{2}, i}\right)^{\prime} .
$$

The Markov transition matrix for married households, $\Pi_{\left(e_{1}, e_{2}\right), i}=\left[\pi\left(e_{1, i+1}^{j^{\prime}}, e_{2, i+1}^{k^{\prime}} \mid e_{1, i}^{j}, e_{2, i}^{k}\right)\right]$, that corresponds to $\rho=0.87$ and $\operatorname{corr}\left(e_{1}, e_{2}\right)=\omega$ is constructed as

$$
\begin{aligned}
& \pi\left(e_{1, i+1}^{j^{\prime}}, e_{2, i+1}^{k^{\prime}} \mid e_{1, i}^{j}, e_{2, i}^{k}\right) \\
& \quad= \begin{cases}\hat{\omega} \mathbf{1}_{\left\{j^{\prime}=k^{\prime}\right\}} \pi\left(e_{1, i+1}^{j} \mid e_{1, i}^{k}\right)+(1-\hat{\omega}) \pi\left(e_{1, i+1}^{j^{\prime}} \mid e_{1, i}^{j}\right) \pi\left(e_{2, i+1}^{k^{\prime}} \mid e_{2, i}^{k}\right) & \text { if } j=k, \\
\pi\left(e_{1, i+1}^{j^{\prime}} \mid e_{1, i}^{j}\right) \pi\left(e_{2, i+1}^{k^{\prime}} \mid e_{2, i}^{k}\right) & \text { if } j \neq k,\end{cases}
\end{aligned}
$$

where $\hat{\omega}$ is the conditional probability for a married household to be a perfectly-correlated household given that they are on the diagonal, $j=k$,

$$
\hat{\omega}=\frac{\omega}{\omega+(1-\omega)\left(\pi_{e_{1}, i}\right)^{\prime}\left(\pi_{e_{2}, i}\right)} .
$$

According to Hyslop (2001), the correlation between male and female wages (earnings) of married households with both spouses working is $0.340(0.246)$. Assuming that the correlation between (potential) wages of households with only one of those working is smaller, in this paper, the intrafamily earning-ability correlation is set to be $\omega=0.25$.

In the model economy, the household's minimum wealth level depends only on its age as $a^{\prime} \geq a_{\min }^{\prime}(\mathbf{s})=$ $a_{\min }^{\prime}(i)$, and

$$
a_{\min }^{\prime}(i)= \begin{cases}{\left[(1+\mu) a_{\min }(i+1)-0.07 \bar{w} e_{1, i+1}^{1} h_{\max }\right] /(1+\bar{r})} & \text { if } \quad i=21, \ldots, I-1 \\ 0 & \text { if } \quad i=I\end{cases}
$$

where $e_{1, i+1}^{1}$ is the lowest male working ability of age $i+1$, and where $\bar{r}, \bar{w}$, and $\bar{h}$ are the interest rate, the wage rate, and the average working hours, respectively, in the baseline economy. One might expect minimum assets to be set at what a household could repay under the worst possible realizations for working ability, which is known as the natural borrowing constraint. However, labor income with the lowest working ability and with longest working hours is instead multiplied by 0.07 to align household debt to the U.S. economy. According to the 2010 SCF (FRB, 2012), 11.0\% of households have negative net worth, and 
Figure 4: The Marginal Income Tax Rate Schedule of Married and Single Households
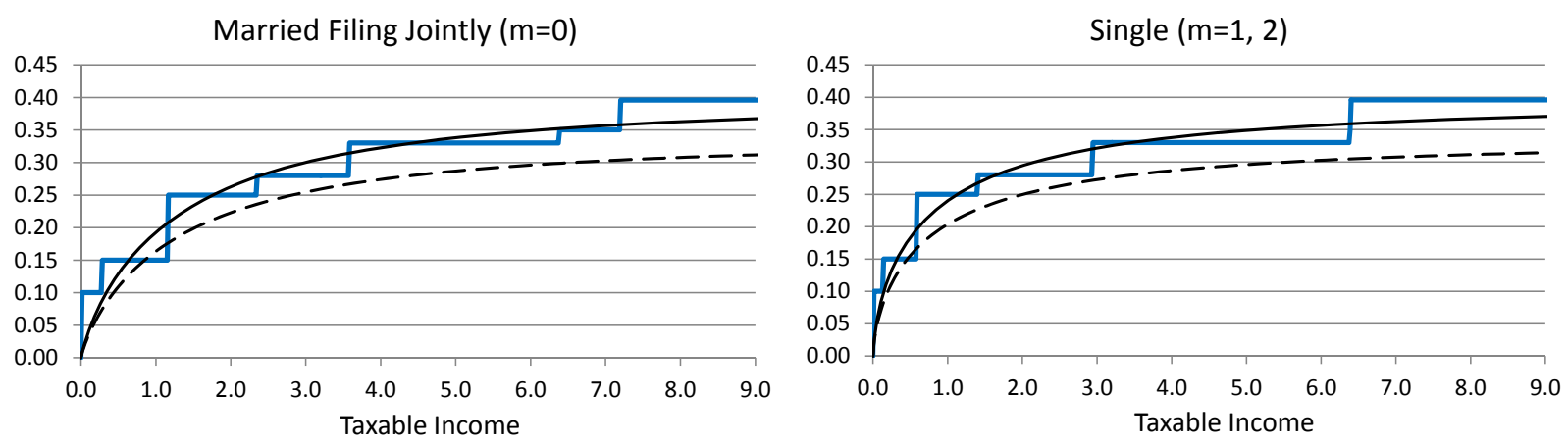

—Statutory Rates _-Estimated Rates (OLS) - - Effective Rates

their average net debt is $\$ 31,447$ ( $\$ 3,459$ per household). In the model economy, $23.3 \%$ of households have negative wealth, and their average debt corresponds to $\$ 14,849$ ( $\$ 3,460$ per household).

\subsection{The Government's Policy Functions}

The parameters of the Gouveia-Strauss type individual income tax function are estimated by OLS using statutory marginal tax rates in 2013. One of the parameters, $\varphi_{t}$, is the limit of the marginal tax rate as taxable income goes to infinity. Thus, $\varphi_{t}$ is first set at 0.396 , the highest marginal tax rate in 2013 . The other two parameters, $\varphi_{m, 1}$ and $\varphi_{m, 2}$, are estimated by OLS (equally weighted for taxable income between $\$ 0$ and $\$ 600,000)$, separately for both married households filing jointly and single households. Then, $\varphi_{t}$ is adjusted to 0.3360 to reflect effective income tax rates and to make the individual income tax revenue, $T_{I, t}, 10.0 \%$ of GDP in the baseline economy. Figure 4 indicates the statutory and estimated marginal income tax rates.

The OASI payroll tax rate is $5.3 \%$ for an employee and $5.3 \%$ for an employer. Thus, $\bar{\tau}_{P, t}$ is set at $0.106 / 1.053=0.1007$. The thresholds to calculate primary insurance amounts (PIA) are set for each of the age cohorts when they reach age 62 in the U.S. system. For simplicity, the growth-adjusted thresholds for all the age cohorts are fixed in the model economy, and the PIA of each age cohort is adjusted later by using the long-term productivity growth rate and the number of the years from age 60 . Thus, after a scale adjustment, the model simply uses the thresholds for the 62-year-old cohort in 2013. The OASDI benefit adjustment factor, $\psi_{t}$, is 1.0 in the baseline economy. To balance the OASI budget, the OASI residual, $T R_{O}$, is set at 0.2456 , which is $5.7 \%$ of the OASI payroll tax revenue in the baseline economy. This residual includes Social Security benefits received by the children and parents of the workers as well as administration cotst, 
Table 3: The Shares of OASI Benefits by Type of Recipients (percent)

\begin{tabular}{lrrr}
\hline \hline Year & $\begin{array}{r}\text { Retired } \\
\text { workers }\end{array}$ & $\begin{array}{r}\text { Wives and } \\
\text { husbands }\end{array}$ & $\begin{array}{r}\text { Widows and } \\
\text { widowers }\end{array}$ \\
\hline 2008 & 78.9 & 4.5 & 16.6 \\
2009 & 79.5 & 4.4 & 16.1 \\
2010 & 80.1 & 4.3 & 15.5 \\
2011 & 80.6 & 4.2 & 15.1 \\
2012 & 81.2 & 4.1 & 14.7 \\
$2008-2012$ average & 80.1 & 4.3 & 15.6 \\
\hline Baseline & 80.5 & 3.9 & 15.6 \\
\hline \hline
\end{tabular}

Source: Author's calculations from Table 4.A5 in Social Security Administration (2014).

which are abstracted from in this paper.

\subsection{Baseline Economy}

Table 3 shows the shares of OASI benefits by type of recipients in the data (Social Security Administration, 2014) and the baseline economy. The calibration targets are the shares in 2012 and the averages in the recent five years. The shares of the old-age retirement benefits, spousal benefits, and survivors benefits (received by spouses) are $80.5 \%, 3.9 \%$, and $15.6 \%$, respectively. The first and third numbers are within the ranges of corresponding target values, but the share of the spousal benefits, $3.9 \%$, in the baseline economy is smaller than the share, $4.1 \%$, in the 2012 data. Yet, the baseline economy captures the Social Security's spousal and survivors benefits fairly well ${ }^{16}$

Figure 5 shows the labor participation rates by age of men and women in the data (Bureau of Labor Statistics, 2013) and the baseline economy. As explained above, the average labor participation rates of men and women ages $25-54$ are targeted to $88.7 \%$ and $74.5 \%$, respectively. So, the model economy captures the labor force participation rates of men and women ages $25-54$ well. However, the model is not very successful to replicate the lower labor force participation rates of those ages 20-24 and ages 55 and older.

There are several reasons for this inconsistency. First, the model in this paper does not incorporate the household's demand for schooling and a possible financial assistance from their parents. So, in the model economy, young households with no or little wealth tend to work even if their wages are relatively

\footnotetext{
${ }^{16}$ The shares of the spousal and survivors benefits are both declining in recent years. The share of the spousal benefits will likely decrease in the near future, too, as the gender wage gap has been narrowing in recent decades. It is not clear, however, if the share of the survivors benefits will continue decreasing. The share is declining in recent years partly because baby-boom generations have recently retired and started receiving Social Security benefits, but they are still too young to receive survivors benefits.
} 
Figure 5: The Labor Force Participation Rates by Age

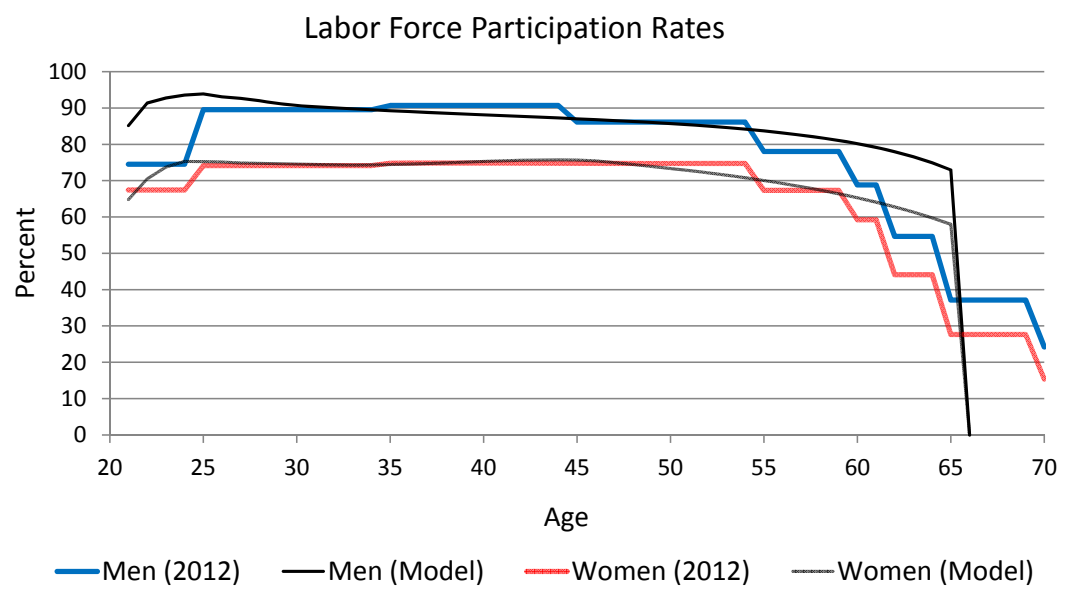

Source: Table 3.3 in Bureau of Labor Statistics (2013) and author's calculations.

low. Second, the model does not incorporate the health condition of the households when they get older. The health condition would affect not only their wages but also the disutility from working. For those households ages 55 and older, their decisions on labor participation and retirement depends strongly on their health condition, the availability of health insurance, and the eligibility of disability insurance. However, in the model economy, the average timing of the retirement of workers as well as the average labor force participation of those ages 55-70 are roughly consistent with the data.

\section{Removing Spousal and Survivors Benefits}

The policy experiments in this paper are straightforward. The economy is assumed to be in the initial steady-state equilibrium (and on the balanced growth path) in year 0. Starting at the beginning of year 1, the government removes the spousal and survivors benefits of the current OASI program cohort by cohort in a phased-in manner.

More specifically, for households ages 61 or older in year 1, their OASI benefit function is unchanged because it is too late for these households to adjust their labor supply to the policy change. Thus, for $i-(t-1) \geq 61$ and $1 \leq t \leq I-60=40$,

$$
\operatorname{tr}_{S S, t}^{0}\left(i, b_{1}, b_{2}, m\right)= \begin{cases}\psi_{t}\left(\psi_{0} / \psi_{T}\right) \max \left[\psi\left(i, b_{1}\right)+\psi\left(i, b_{2}\right), 1.5 \psi\left(i, b_{1}\right), 1.5 \psi\left(i, b_{2}\right)\right] & \text { if } m=0 \\ \psi_{t}\left(\psi_{0} / \psi_{T}\right) \max \left[\psi\left(i, b_{1}\right), \psi\left(i, b_{2}\right)\right] & \text { if } m=1,2\end{cases}
$$


where $\psi_{0}$ and $\psi_{T}$ are benefit adjustment parameters in the initial steady state and the final steady state, respectively, and $\psi_{t}$ is adjusted to balance the OASI budget in each transition period. Because the government introduces the policy change cohort by cohort, most current households continue receiving (part of) spousal and survivors benefits. To keep generational equity, in this experiment, the government first discounts the benefits under the old schedule with $\psi_{0} / \psi_{T}$, then it adjusts all benefits proportionally with $\psi_{t}$ to balance the Social Security budget each year.

For households ages 21 or younger in year 1, their OASI benefit function is fully replaced by the new benefit function without spousal and survivors benefits, i.e., for $i-(t-1) \leq 21$ and $t \geq I_{R}-20=46$,

$$
\operatorname{tr}_{S S, t}^{1}\left(i, b_{1}, b_{2}, m\right)= \begin{cases}\psi_{t}\left[\psi\left(i, b_{1}\right)+\psi\left(i, b_{2}\right)\right] & \text { if } m=0 \\ \psi_{t} \psi\left(i, b_{j}\right) & \text { if } m=j=1,2\end{cases}
$$

Finally, for households ages 22-60 in year 1, their possible spousal and survivors benefits are reduced linearly cohort by cohort. The OASI benefit function is set as the weighted average of the above two functions, i.e., for $22 \leq i-(t-1) \leq 60$ and $6=I_{R}-60 \leq t \leq I-21=79$,

$$
\operatorname{tr}_{S S, t}\left(i, b_{1}, b_{2}, m\right)=\frac{(i-20)-t}{40} \operatorname{tr}_{S S, t}^{0}\left(i, b_{1}, b_{2}, m\right)+\left(1-\frac{(i-20)-t}{40}\right) \operatorname{tr}_{S S, t}^{1}\left(i, b_{1}, b_{2}, m\right)
$$

The Government's Financing Assumptions. Any changes in the current Social Security system would alter the government's income and payroll tax revenue. If spousal and survivors benefits were eliminated, then all other things being equal, the government's benefit expenditures would decrease and the payroll tax revenue would likely increase because of a larger labor supply. For simplicity, the OASI budget is balanced each year in the model economy, the payroll tax rate, $\bar{\tau}_{P, t}$, is fixed at the baseline level, and the OASI benefits are changed proportionally each year by the adjustment factor, $\psi_{t}$, to match the benefit expenditure to the payroll tax revenue. For the rest of the government budget, the removal of spousal and survivors benefits would likely increase the labor supply, thus increasing individual income tax revenues. The rest of the government budget is also balanced each year, and either the lump-sum transfer, $t r_{L S, t}$, or the marginal income tax rate parameter, $\varphi_{t}$, is changed to balance the budget. The government's financing rules assumed in this paper are summarized as follows:

$$
\operatorname{tr}_{L S, t} \longleftarrow T R_{L S, t}\left(\operatorname{tr}_{L S, t}\right)=T_{I, t}\left(\varphi_{0}\right)-C_{G, 0}+\left(1+r_{t}\right) W_{G, t}-(1+\mu)(1+\nu) W_{G, t+1}
$$


(b)

$$
W_{G, t+1}=W_{G, t}
$$

$$
\begin{gathered}
\varphi_{t} \longleftarrow \quad T_{I, t}\left(\varphi_{t}\right)=C_{G, 0}+T R_{L S, t}\left(\operatorname{tr}_{L S, 0}\right)-\left(1+r_{t}\right) W_{G, t}+(1+\mu)(1+\nu) W_{G, t+1}, \\
W_{G, t+1}=W_{G, t} ;
\end{gathered}
$$

(a) and (b) $\quad \psi_{t} \quad \longleftarrow T R_{S S, t}\left(\psi_{t}\right)=T_{P, t}\left(\bar{\tau}_{P, 0}\right)-T R_{O}$.

Welfare Measure. The change in social welfare by the policy reform is evaluated based on the ex ante expected (remaining) lifetime utility of each age cohort (the veil of ignorance). The welfare gains or losses of age-21 households at the beginning of $t=1, \ldots, \infty$ are calculated as the uniform percentage changes, $\lambda_{21, t}$, in the baseline consumption path, such that these changes would make the household's expected lifetime utility equivalent with the expected utility after the policy change; that is,

$$
\lambda_{21, t}=\left[\left(\frac{E v\left(\mathbf{s}_{21}, \mathbf{S}_{t} ; \mathbf{\Psi}_{t}\right)}{E v\left(\mathbf{s}_{21}, \mathbf{S}_{0} ; \mathbf{\Psi}_{0}\right)}\right)^{\frac{1}{\alpha(1-\gamma)}}-1\right] \times 100
$$

where $\mathbf{s}_{21}=\left(21, a, b_{1}, b_{2}, e_{1}, e_{2}, m\right)$. Similarly, the average welfare changes of households of age $i$ at the time of the policy change $(t=1)$ are calculated as the uniform percent changes, $\lambda_{i, 1}$, which are required in the baseline consumption path so that the rest-of-the-lifetime value would be equal to the rest-of-the-lifetime value after the policy change; that is,

$$
\lambda_{i, 1}=\left[\left(\frac{E v\left(\mathbf{s}_{i}, \mathbf{S}_{1} ; \mathbf{\Psi}_{1}\right)}{E v\left(\mathbf{s}_{i}, \mathbf{S}_{0} ; \mathbf{\Psi}_{0}\right)}\right)^{\frac{1}{\alpha(1-\gamma)}}-1\right] \times 100 .
$$

Note that $\lambda_{i, 1}$ for $i=I, \ldots, 1$ shows the cohort-average welfare changes of all current households alive at the time of the policy change, and $\lambda_{21, t}$ for $t=2, \ldots, \infty$ shows the cohort-average welfare changes of all future households.

\subsection{Long-Run Effects Over the Life Cycle}

Figure 6 shows the long-run effects of removing spousal and survivors benefits over the life cycle. In each of the 8 charts, the solid black line indicates the profile of the main baseline economy; the dashed blue line shows Run 1 (a), in which the government increases lump-sum transfers; and the long-dashed red line shows Run 1 (b), in which the government reduces marginal income tax rates. Figure 7 shows the policy effects as percent changes from the baseline averages. 
Figure 6: The Long-Run Effects of Removing Spousal and Survivors Benefits over the Life Cycle (in model units)
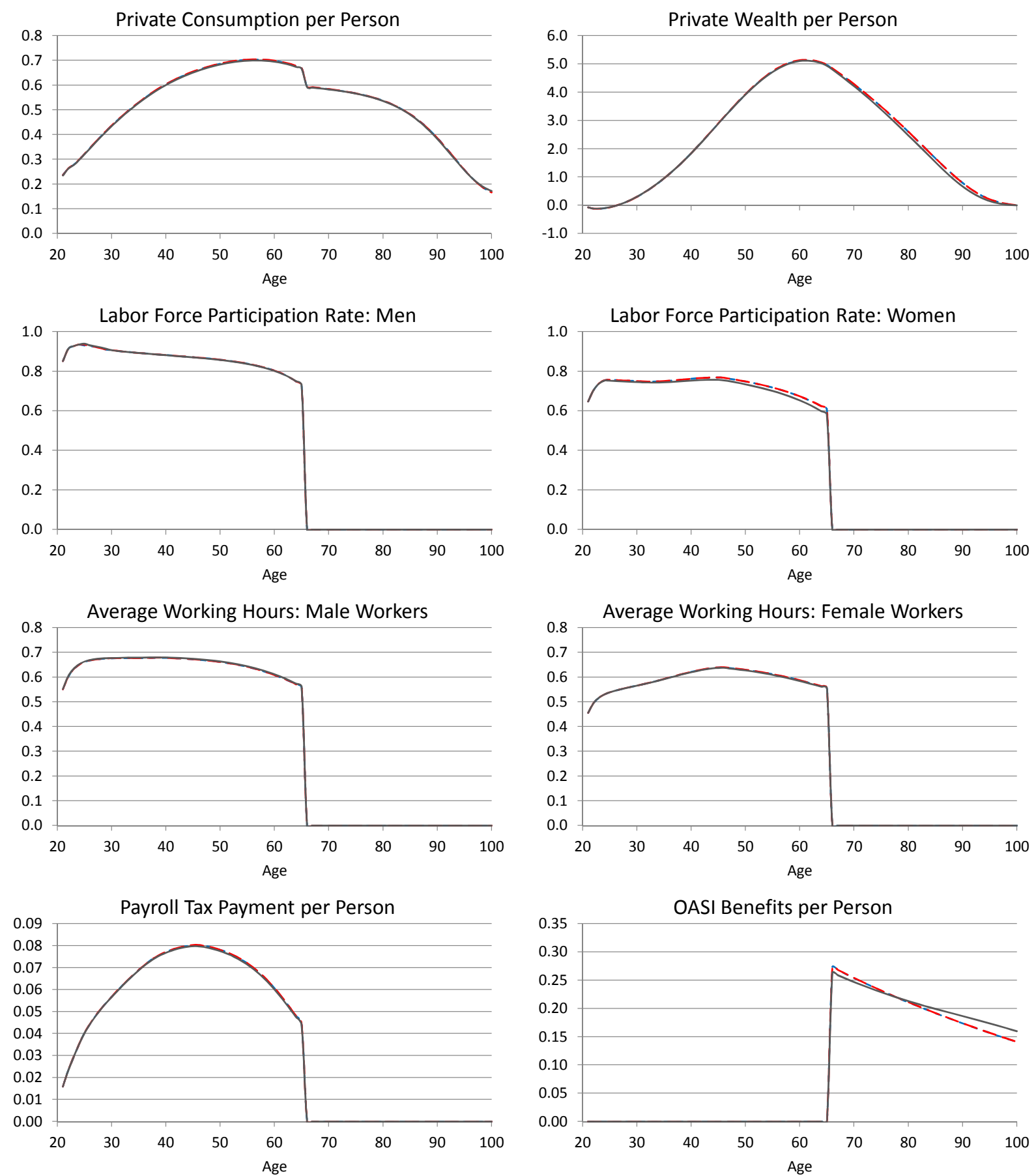

_ Baseline Economy _ - - Increasing Lumpsum Transfers _ - Reducing Marginal Income Tax Rates 
Figure 7: The Long-Run Effects of Removing Spousal and Survivors Benefits over the Life Cycle (changes as a percentage of the baseline average)
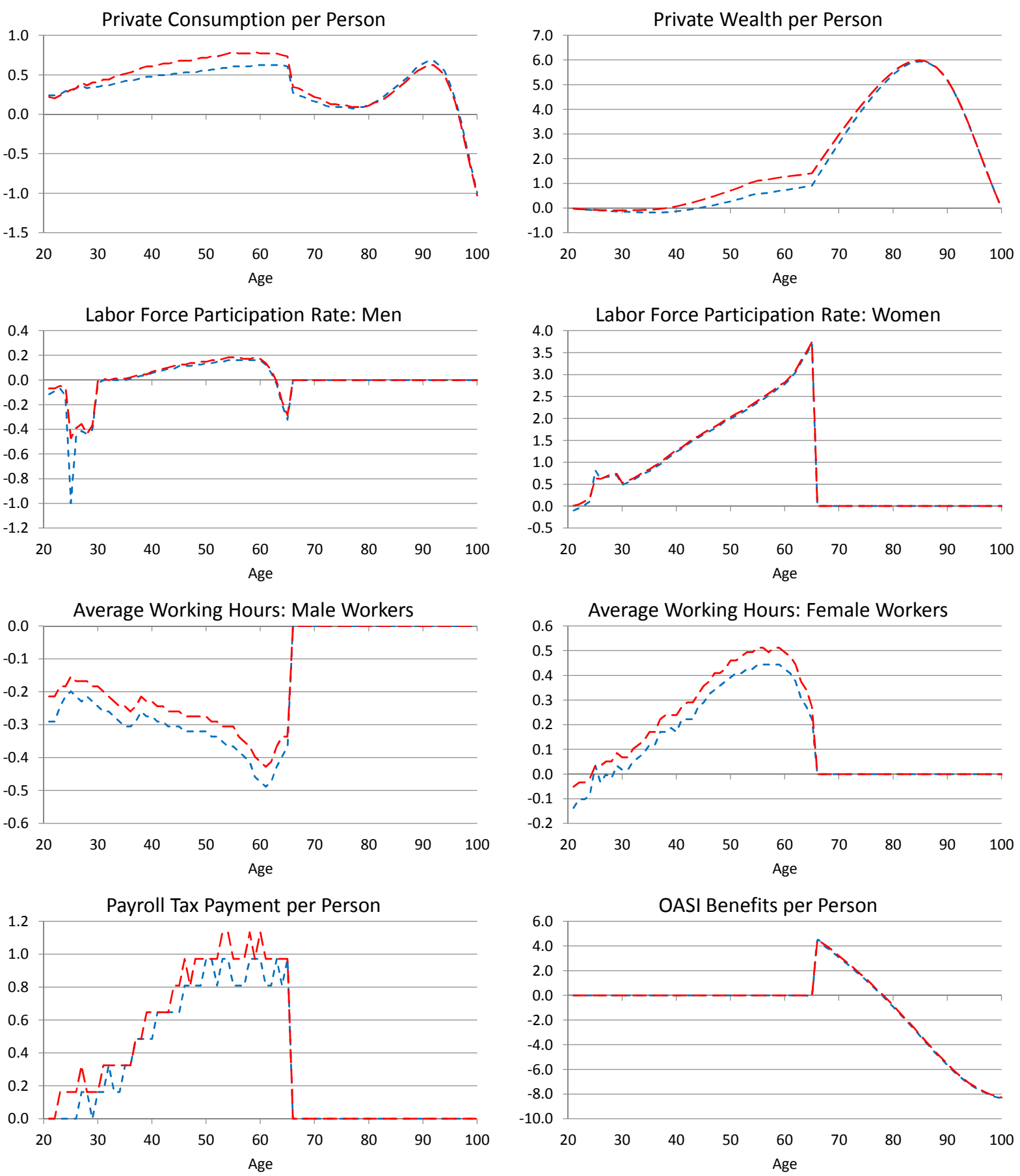

- - - Increasing Lumpsum Transfers

- - Reducing Marginal Income Tax Rates 
When spousal and survivors benefits were replaced with old-age retirement benefits, the labor force participation rate of women ages $21-65$ would increase, on average, by $1.4 \%$ in the long run. The increase in the participation rate becomes larger as women get older, and the participation rate of women of nearretirement age would increase more than $3.0 \%$, because those relatively-old workers can predict their future PIAs more accurately and respond to the policy change. The removal of spousal and survivors benefits would also increase the average working hours of female worker. However, the increase in the average working hours is much smaller than the increase in the participation rate. Whether or not women are working is more important than how many hours they work because OASI benefits are progressive.

The effect of the policy change on the labor supply of men is much smaller than that of women. Only a small number of male workers receive spousal and survivors benefits in the baseline economy, because male wage rates are, on average, about $25 \%$ higher than female wage rates. The labor force participation rate of men ages 21-65 changes very little. The average working hours of male workers decrease slightly because of the higher effective payroll tax rate and the substitution between the husband's work hours and the wife's work hours.

The policy change would increase the total labor supply and the income tax revenue, which would allow the government to increase lump-sum transfers to households or reduce marginal income tax rates. Private consumption would increase, on average, by $0.4-0.5 \%$ in the long run, although consumption of very old households (ages 97-100) would decline because of the removal of survivors benefits. The increase rate is slightly higher when the government reduces marginal income tax rates proportionally to balance the rest of the government budget. Private wealth would increase, on average, by $0.9-1.1 \%$, which increase is mainly generated by the reduction in the Social Security's annuity effect due to the removal of spousal and survivors benefits.

When spousal and survivors benefits were replaced with old-age retirement benefits, the OASI benefits would be, on average, larger for retired households ages 78 or younger but smaller for those ages 79 or older. In the baseline economy, per capita OASI benefits are, on average, increasing by age because some widow(er)s switch their benefits from their own benefits to survivors benefits when their spouses die ${ }^{17}$ After the policy change, the number of widow(er)ed people would increase as households grow older, but their OASI benefits would be lower because of the removal of survivors benefits.

\footnotetext{
${ }^{17}$ In Figure 6 per capita OASI benefits look decreasing by age because the individual variables, except for working hours, are growth-adjusted in the model economy.
} 
Table 4: Long-run Changes in Hours of Market Work of Age-40 Men and Women (changes as a percentage of the average baseline hours)

\begin{tabular}{|c|c|c|c|c|c|c|c|c|c|c|c|c|c|c|}
\hline & & & \multicolumn{6}{|c|}{ Husband or single male } & \multicolumn{6}{|c|}{ Wife or single female } \\
\hline & & & $\begin{array}{r}e_{2}^{1} \\
0.20\end{array}$ & $\begin{array}{r}e_{2}^{2} \\
0.47\end{array}$ & $\begin{array}{r}e_{2}^{3} \\
0.98\end{array}$ & $\begin{array}{r}e_{2}^{4} \\
2.04\end{array}$ & $\begin{array}{r}e_{2}^{5} \\
4.74\end{array}$ & $m=1$ & $\begin{array}{r}e_{2}^{1} \\
0.20\end{array}$ & $\begin{array}{r}e_{2}^{2} \\
0.47\end{array}$ & $\begin{array}{r}e_{2}^{3} \\
0.98\end{array}$ & $\begin{array}{r}e_{2}^{4} \\
2.04\end{array}$ & $\begin{array}{r}e_{2}^{5} \\
4.74\end{array}$ & $m=1$ \\
\hline Run 1 (a) & $e_{1}^{1}$ & 0.25 & -0.4 & -0.3 & 0.2 & 0.1 & 0.0 & 0.0 & 0.2 & 0.2 & -0.1 & -0.3 & 0.0 & - \\
\hline Increasing & $e_{1}^{2}$ & 0.59 & -0.4 & -0.5 & -0.4 & 0.6 & 1.7 & 0.0 & 1.4 & 1.3 & 0.4 & -0.1 & 0.0 & - \\
\hline lump-sum & $e_{1}^{3}$ & 1.22 & -0.6 & -0.7 & -0.7 & -0.4 & 0.7 & -0.1 & 0.5 & 3.6 & 2.1 & 0.4 & -0.1 & - \\
\hline \multirow{3}{*}{ transfers } & $e_{1}^{4}$ & 2.54 & 0.3 & 0.2 & 0.0 & -0.1 & -0.4 & -0.2 & 0.0 & 4.7 & 5.0 & 2.5 & -0.1 & - \\
\hline & $e_{1}^{5}$ & 5.91 & 0.3 & 0.2 & 0.1 & 0.0 & 0.0 & -0.3 & 0.0 & 0.2 & 6.9 & 4.5 & 0.5 & - \\
\hline & $m=2$ & & - & - & - & - & - & & 0.1 & 0.1 & 0.0 & -0.1 & -0.3 & \\
\hline Run 1 (b) & $e_{1}^{1}$ & 0.25 & -0.3 & -0.2 & 0.3 & 0.1 & 0.0 & 0.1 & 0.4 & 0.3 & 0.0 & -0.3 & 0.1 & - \\
\hline Reducing & $e_{1}^{2}$ & 0.59 & -0.4 & -0.5 & -0.3 & 0.7 & 1.8 & 0.1 & 1.5 & 1.4 & 0.4 & -0.1 & 0.0 & - \\
\hline income & $e_{1}^{3}$ & 1.22 & -0.6 & -0.6 & -0.6 & -0.3 & 0.8 & 0.0 & 0.5 & 3.7 & 2.2 & 0.4 & 0.0 & - \\
\hline \multirow[t]{3}{*}{ tax rates } & $e_{1}^{4}$ & 2.54 & 0.3 & 0.2 & 0.1 & -0.1 & -0.3 & -0.2 & 0.0 & 4.8 & 5.1 & 2.6 & 0.0 & - \\
\hline & $e_{1}^{5}$ & 5.91 & 0.4 & 0.3 & 0.2 & 0.1 & 0.0 & -0.2 & 0.0 & 0.2 & 7.0 & 4.7 & 0.6 & - \\
\hline & $m=2$ & & - & - & - & - & - & & 0.2 & 0.2 & 0.1 & 0.0 & -0.2 & \\
\hline
\end{tabular}

Rows, $e_{1}^{1}, \ldots, e_{1}^{5}$, are male wage levels at age 40 from the lowest to the highest, and columns, $e_{2}^{1}, \ldots, e_{2}^{5}$, are female wage levels at age 40 .

Table 4 shows the long-run changes in the working hours of age-40 married and single households from the baseline economy. Rows, $e_{1}^{1}, \ldots, e_{1}^{5}$, are the husband's wage levels at age 40 , and the columns, $e_{2}^{1}, \ldots, e_{2}^{5}$, are the wife's wage levels. Column $m=1$ and row $m=2$ show the changes in working hours of single male and female households, respectively. Because some people do not work outside the home, the changes in the market work hours of husbands and wives are calculated as percentages of the average market hours of 40-year-old men and women, respectively, before the policy change.

Under both financing assumptions, the working hours of a majority of married men of age 40 would decrease slightly as the working hours of their wives increase. However, the working hours of married men with higher wage rates coupled with women with lower wage rates, e.g., $\left(e_{1}^{4}, e_{2}^{1}\right),\left(e_{1}^{5}, e_{2}^{1}\right)$, and $\left(e_{1}^{5}, e_{2}^{2}\right)$, and married men with lower wage rates coupled with women with higher wage rates, e.g., $\left(e_{1}^{2}, e_{2}^{4}\right),\left(e_{1}^{2}, e_{2}^{5}\right)$, and $\left(e_{1}^{3}, e_{2}^{5}\right)$, would increase. Married men with the lowest wage rate coupled with women with the highest wage rate, $\left(e_{1}^{1}, e_{2}^{5}\right)$, would not work before and after the policy change, thus there would be no change in their working hours. The working hours of single men would increase slightly if their wage rates are relatively lower but decrease slightly if their wage rates are higher.

The working hours of most married women of age 40 would increase more significantly. The changes are especially large for married women with moderate wage rates coupled with men with relatively high 
wage rates, e.g., $\left(e_{1}^{4}, e_{2}^{2}\right),\left(e_{1}^{4}, e_{2}^{3}\right),\left(e_{1}^{5}, e_{2}^{3}\right)$, and $\left(e_{1}^{5}, e_{2}^{4}\right)$, because these women are affected most by the removal of spousal and survivors benefits. The working hours of married women with the lowest wage rate coupled with men with higher wage rates, $\left(e_{1}^{4}, e_{2}^{1}\right)$ and $\left(e_{1}^{5}, e_{2}^{1}\right)$, would not work before and after the policy change, thus there would be no change in their working hours. The working hours of single women would also increase slightly if their wage rates are relatively lower but decrease slightly if their wage rates are higher.

\subsection{Transition Effects on Macro Economy and Welfare}

Table 5 and Figure 8 show the transition effects of removing spousal and survivors benefits from the current OASI program. In each of these 10 charts in Figure 8, the dashed blue line indicates the percentage changes from the baseline economy in Run 1 (a) with increasing lump-sum transfers, and the long-dashed red line indicates the percentage changes in Run 1 (b) with reducing income tax rates.

The total working hours of women would increase by $0.5 \%$ in the first year of the policy change and by $1.6-1.7 \%$ in the long run, relative to the baseline level. The increase in female working hours would be slightly larger in Run 1 (b) because of the lower marginal income tax rates. The labor force participation rate of women would increase by $1.4 \%$ in the long run, but the average working hours of female workers would increase only by $0.2-0.3 \%$ in the long run. As explained in the above, this is due partly to the current progressive Social Security benefit schedule. If married women do not work at all, after the removal of spousal and survivors benefits, they will not receive any OA benefits. However, if they work part time even at lower wages, they will still be eligible for relatively large OA benefits.

The labor force participation rate of men would change very little by the policy change. The total male working hours as well as the average working hours of male workers would decrease by 0.3 under both financing assumptions in the long run.

The total labor supply in efficiency units would increase by $0.3-0.4 \%$ in the long run. The increase is relatively small because women with lower wage rates tend to increase their working hours more than women with higher wage rates after the policy change. Thus, the productivity-weighted labor supply would not increase as much as the total working hours of men and women combined. The capital stock (national wealth) would increase by $0.8-1.0 \%$, and the total output (gross domestic product) would increase by $0.5-$ $0.6 \%$ in the long run. Because of the increased economic activity, OASI payroll tax revenue would increase by $0.5-0.6 \%$ in the long run even though the payroll tax rate is kept at the same level. When spousal and 
Table 5: The Effects of Removing Spousal and Survivors Benefits (\% changes from the baseline economy)

\begin{tabular}{|c|c|c|c|c|c|c|c|}
\hline \multirow{2}{*}{ Run 1 (a) Increasing lump-sum transfers } & \multicolumn{6}{|c|}{ Year } & \multirow{2}{*}{ Long Run } \\
\hline & 1 & 6 & 11 & 21 & 51 & 81 & \\
\hline Capital stock (national wealth) & 0.0 & 0.0 & 0.1 & 0.2 & 0.7 & 0.8 & 0.8 \\
\hline Labor supply (in efficiency units) & 0.1 & 0.1 & 0.2 & 0.2 & 0.3 & 0.3 & 0.3 \\
\hline Gross domestic product & 0.1 & 0.1 & 0.1 & 0.2 & 0.4 & 0.5 & 0.5 \\
\hline Private Consumption & 0.1 & 0.1 & 0.1 & 0.2 & 0.4 & 0.4 & 0.4 \\
\hline Interest rate & 0.1 & 0.2 & 0.1 & 0.0 & -0.6 & -0.8 & -0.8 \\
\hline Average wage rate & 0.0 & 0.0 & 0.0 & 0.0 & 0.1 & 0.2 & 0.2 \\
\hline Welfare of age- 21 households & 0.1 & 0.1 & 0.1 & 0.2 & 0.4 & 0.5 & 0.5 \\
\hline Transfer spending ${ }^{a}$ & 0.1 & 0.2 & 0.2 & 0.4 & 0.5 & 0.5 & 0.5 \\
\hline Marginal income tax rate & 0.0 & 0.0 & 0.0 & 0.0 & 0.0 & 0.0 & 0.0 \\
\hline OASI payroll tax revenue & 0.1 & 0.1 & 0.2 & 0.3 & 0.5 & 0.5 & 0.5 \\
\hline OASI benefit adjustment & 8.3 & 8.4 & 8.4 & 8.2 & 7.9 & 8.3 & 8.3 \\
\hline Labor supply: men & -0.1 & -0.1 & -0.1 & -0.2 & -0.2 & -0.2 & -0.2 \\
\hline Labor supply: women & 0.3 & 0.5 & 0.6 & 0.8 & 1.1 & 1.1 & 1.1 \\
\hline Total working hours: men & -0.1 & -0.2 & -0.2 & -0.3 & -0.3 & -0.3 & -0.3 \\
\hline Total working hours: women & 0.5 & 0.7 & 0.9 & 1.2 & 1.6 & 1.6 & 1.6 \\
\hline Labor participation rate: men & 0.0 & 0.0 & 0.0 & 0.0 & 0.0 & 0.0 & 0.0 \\
\hline Labor participation rate: women & 0.4 & 0.6 & 0.7 & 1.0 & 1.4 & 1.4 & 1.4 \\
\hline Average work hours: male workers & -0.1 & -0.1 & -0.2 & -0.2 & -0.3 & -0.3 & -0.3 \\
\hline Average work hours: female workers & 0.1 & 0.1 & 0.1 & 0.2 & 0.2 & 0.2 & 0.2 \\
\hline \multirow{2}{*}{ Run 1 (b) Reducing income tax rates } & \multicolumn{6}{|c|}{ Year } & \multirow{2}{*}{ Long Run } \\
\hline & 1 & 6 & 11 & 21 & 41 & 81 & \\
\hline Capital stock (national wealth) & 0.0 & 0.1 & 0.1 & 0.3 & 0.9 & 1.0 & 1.0 \\
\hline Labor supply (in efficiency units) & 0.1 & 0.1 & 0.2 & 0.3 & 0.4 & 0.4 & 0.4 \\
\hline Gross domestic product & 0.1 & 0.1 & 0.2 & 0.3 & 0.6 & 0.6 & 0.6 \\
\hline Private Consumption & 0.1 & 0.1 & 0.1 & 0.2 & 0.4 & 0.5 & 0.5 \\
\hline Interest rate & 0.2 & 0.1 & 0.1 & -0.1 & -0.9 & -1.1 & -1.1 \\
\hline Average wage rate & 0.0 & 0.0 & 0.0 & 0.0 & 0.2 & 0.2 & 0.2 \\
\hline Welfare of age- 21 households & 0.0 & 0.0 & 0.1 & 0.1 & 0.4 & 0.4 & 0.4 \\
\hline Transfer spending ${ }^{a}$ & 0.0 & 0.0 & 0.0 & 0.0 & 0.0 & 0.0 & 0.0 \\
\hline Marginal income tax rate & -0.1 & -0.2 & -0.3 & -0.5 & -0.6 & -0.6 & -0.6 \\
\hline OASI payroll tax revenue & 0.1 & 0.1 & 0.2 & 0.3 & 0.6 & 0.6 & 0.6 \\
\hline OASI benefit adjustment & 8.4 & 8.5 & 8.5 & 8.3 & 8.0 & 8.3 & 8.3 \\
\hline Labor supply: men & -0.1 & -0.1 & -0.1 & -0.1 & -0.2 & -0.2 & -0.2 \\
\hline Labor supply: women & 0.4 & 0.5 & 0.6 & 0.9 & 1.2 & 1.2 & 1.2 \\
\hline Total working hours: men & -0.1 & -0.1 & -0.2 & -0.2 & -0.2 & -0.3 & -0.3 \\
\hline Total working hours: women & 0.5 & 0.7 & 0.9 & 1.3 & 1.7 & 1.7 & 1.7 \\
\hline Labor participation rate: men & 0.0 & 0.0 & 0.0 & 0.0 & 0.0 & 0.0 & 0.0 \\
\hline Labor participation rate: women & 0.4 & 0.6 & 0.8 & 1.1 & 1.4 & 1.4 & 1.4 \\
\hline Average work hours: male workers & -0.1 & -0.1 & -0.1 & -0.2 & -0.2 & -0.3 & -0.3 \\
\hline Average work hours: female workers & 0.1 & 0.1 & 0.2 & 0.2 & 0.3 & 0.3 & 0.3 \\
\hline
\end{tabular}

${ }^{a}$ Changes as percentages of the baseline income tax revenue. 
Figure 8: The Transition Effects of Removing Spousal and Survivors Benefits
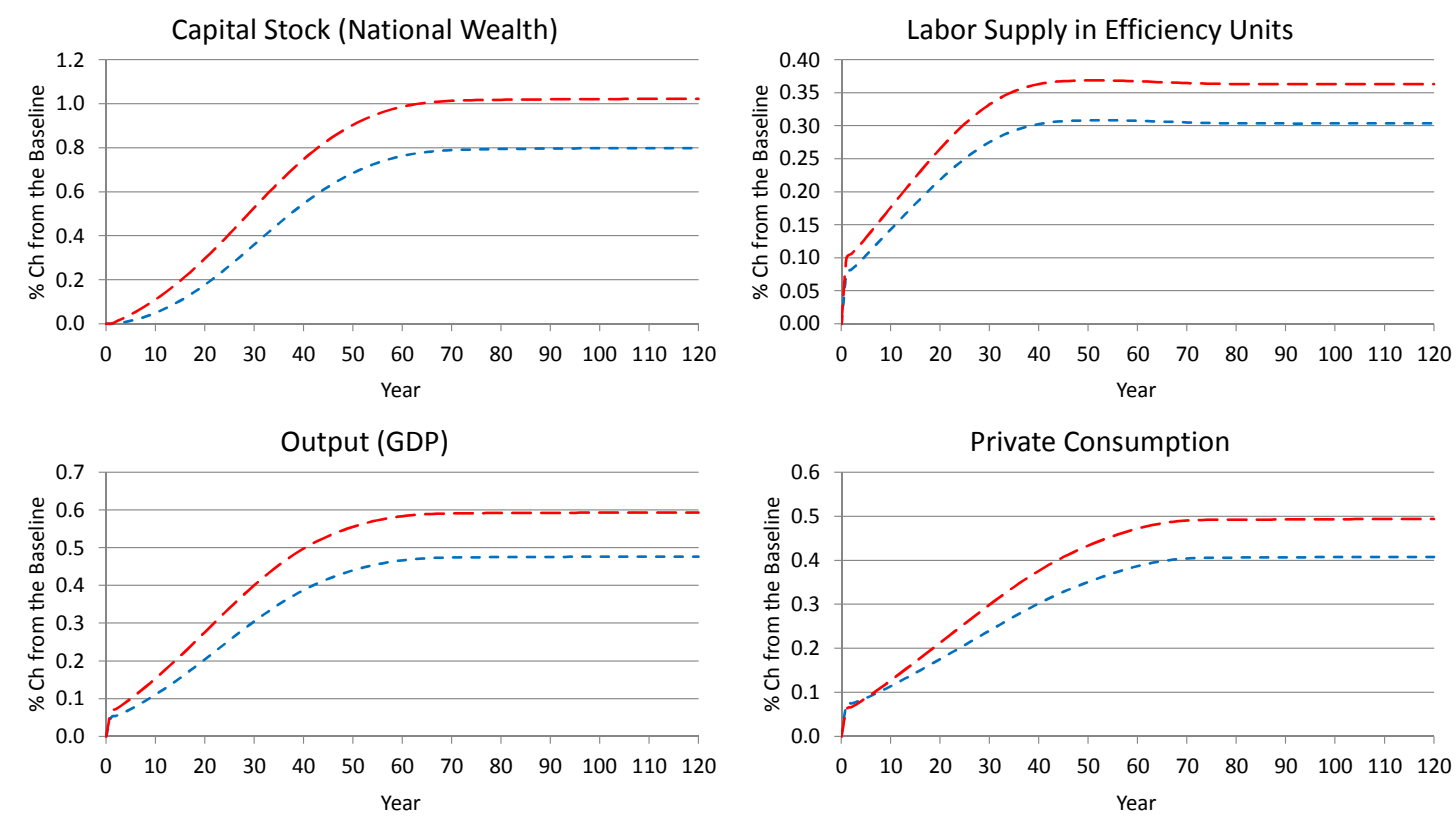

Labor Force Participation Rate: Men

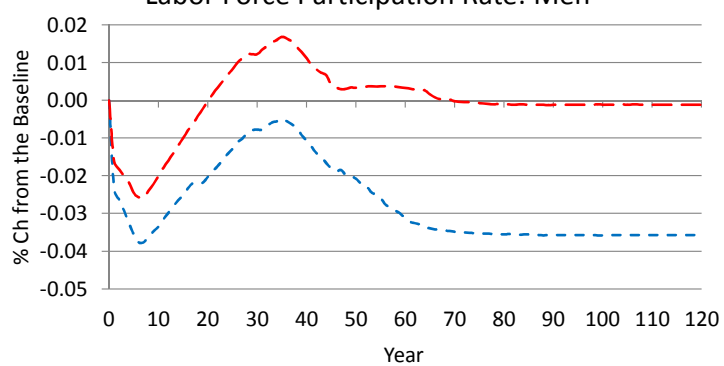

Labor Force Participation Rate: Women

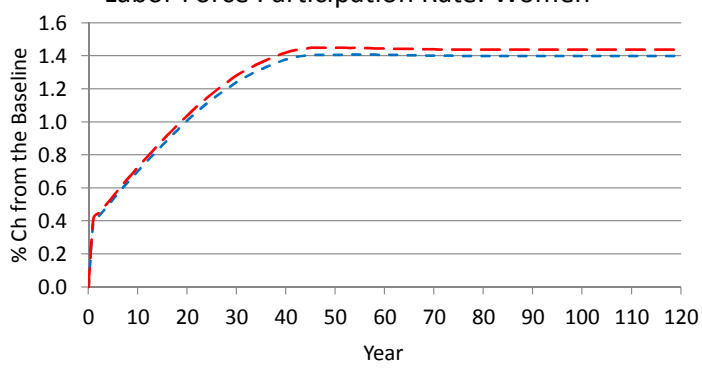

Average Working Hours: Male Workers

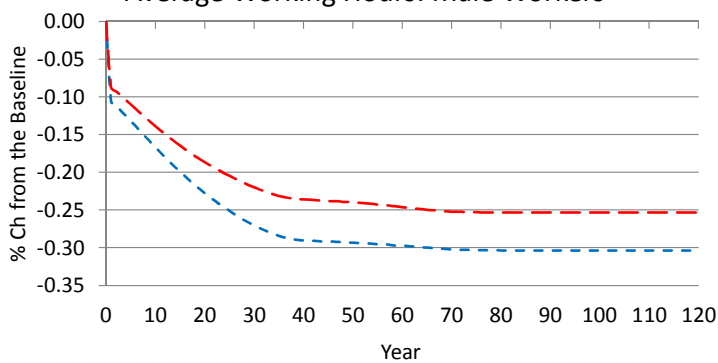

Average Working Hours: Female Workers
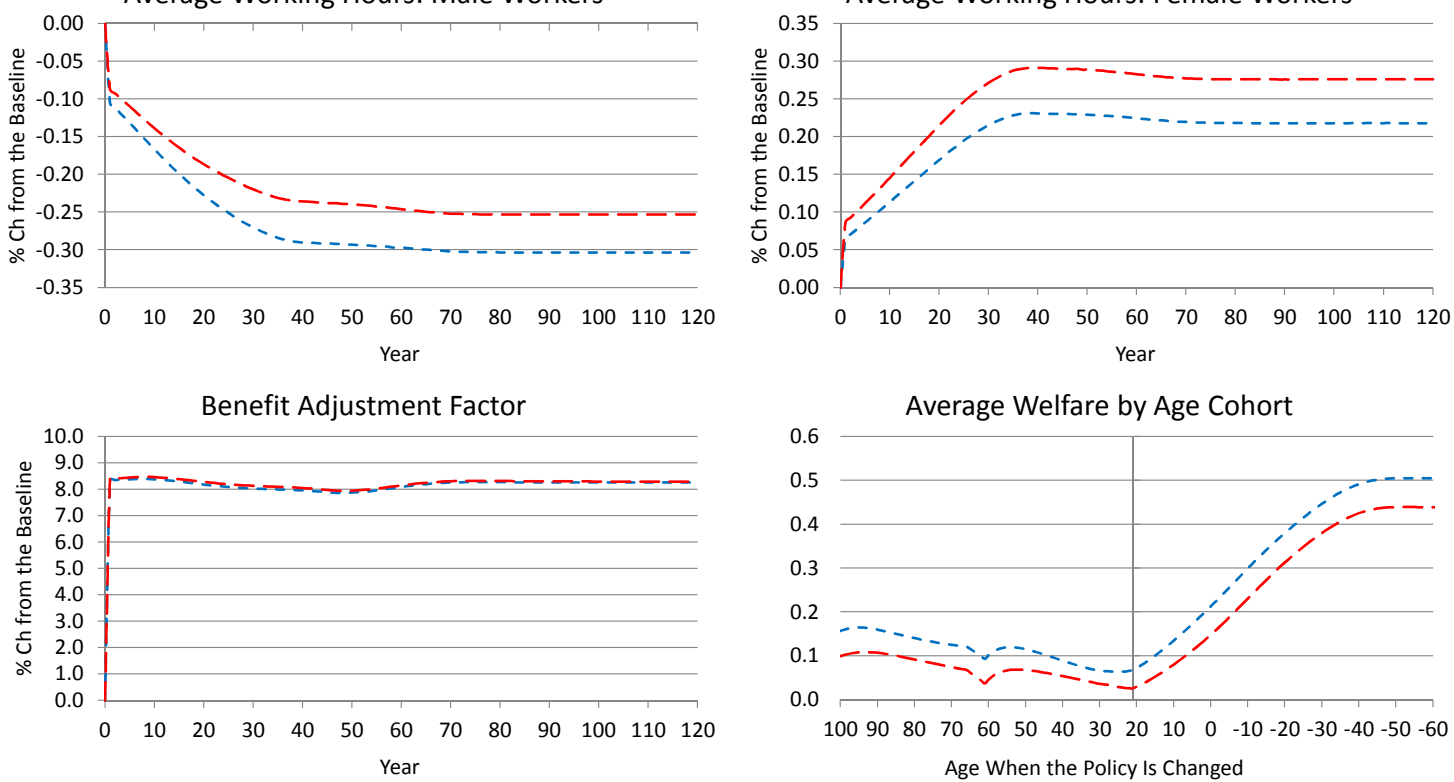

Average Welfare by Age Cohort

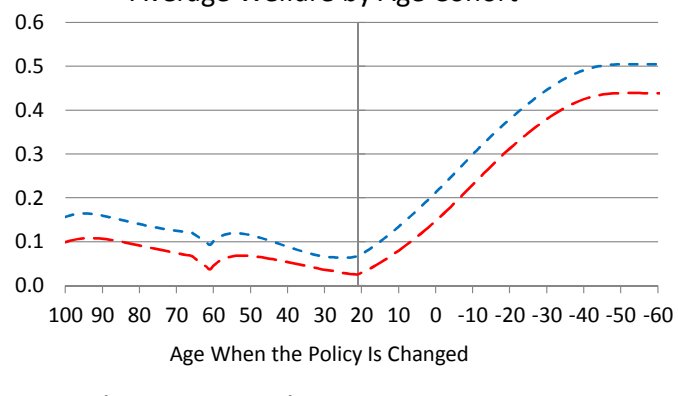

- - Reducing Marginal Income Tax Rates 
survivors benefits were removed, the government could increase the old-age retirement benefits by $7.9-8.5 \%$ during the transition path and by $8.3 \%$ in the long run to balance the Social Security budget.

The bottom right chart in Figure 8 shows the average welfare change by age cohort. The horizontal axis is the age of the households when the policy is changed (in year 1). The vertical line in the middle indicates the youngest age cohort (age-21 households) at the time of the policy change. Households shown to the left of the vertical line are current households ages 21-100 at the time of the policy change, and those households shown to the right of the vertical line are future households ages 20 and younger at the time of the policy change.

The current elderly households ages 61 and older would be aided by the policy change. Their OASI benefit function is unaffected by the policy change, but their OASI benefits would increase slightly because of the higher payroll tax revenue due to the larger labor supply. The interest income would also increase in the short run. These households also receive higher lump-sum transfers or pay lower income taxes. The spousal and survivors benefits of current households ages 22-60 are partially replaced with the OA benefits, depending on their age in year 1. Due to the phased-in policy change, the welfare gains of these households would be smaller for younger households. Because of the higher economic activity and the lower distortion from the Social Security benefit schedule, the economy grows gradually over the transition path. Future newborn (age-21) households would be, on average, better off by $0.4-0.5 \%$ in the long run with the consumption equivalence measure.

Even in the short run before the economy fully grows, the phased-in replacement of the spousal and survivors benefits with the OA benefits would make all age cohorts, on average, better off, although the policy change would make a majority of young married households worse off in the short run (See Table 6).

Table 6 shows the welfare gains and losses of 21-year-old households in year 1 and in the long run by their initial wage level. Rows, $e_{1}^{1}, \ldots, e_{1}^{5}$, correspond to the husband's wage levels at age 21 , and the columns, $e_{2}^{1}, \ldots, e_{2}^{5}$, correspond to the wife's wage levels at age 21 . Column $m=1$ and row $m=2$ and show the welfare gains and losses of single male and female households, respectively. Under both financing assumptions, the policy change-removing spousal and survivors benefits—would hurt a majority of married households at age 21 in the short run, but the policy change would aid most married households in the long run. All single households of age 21 would be better off both in the short run and in the long run.

Married households of age 21 would be worse off significantly if the husband's wage rate is high and the wife's wage rate is low, e.g., $\left(e_{1}^{4}, e_{2}^{1}\right),\left(e_{1}^{5}, e_{2}^{1}\right)$, and $\left(e_{1}^{5}, e_{2}^{2}\right)$. Some married households with the highest-wage 
Table 6: Welfare Change of Age-21 Households in the Transition Path

\begin{tabular}{|c|c|c|c|c|c|c|c|c|c|c|c|c|c|c|}
\hline & & & \multicolumn{6}{|c|}{ At the policy change $(t=1)$} & \multicolumn{6}{|c|}{ In the final steady state $(t=\infty)$} \\
\hline & & & $e_{2}^{1}$ & $e_{2}^{2}$ & $e_{2}^{3}$ & $e_{2}^{4}$ & $e_{2}^{5}$ & $m=1$ & $e_{2}^{1}$ & $e_{2}^{2}$ & $e_{2}^{3}$ & $e_{2}^{4}$ & $e_{2}^{5}$ & $m=1$ \\
\hline & & & 0.09 & 0.16 & 0.28 & 0.48 & 0.90 & & 0.09 & 0.16 & 0.28 & 0.48 & 0.90 & \\
\hline Run 1 (a) & $e_{1}^{1}$ & 0.09 & 0.0 & 0.0 & 0.0 & 0.0 & 0.0 & 0.4 & 0.6 & 0.6 & 0.5 & 0.5 & 0.4 & 1.0 \\
\hline Increasing & $e_{1}^{2}$ & 0.18 & -0.1 & -0.1 & 0.0 & 0.0 & 0.0 & 0.4 & 0.4 & 0.5 & 0.4 & 0.4 & 0.4 & 0.9 \\
\hline lump-sum & $e_{1}^{3}$ & 0.30 & -0.2 & -0.2 & -0.1 & 0.0 & 0.0 & 0.5 & 0.3 & 0.3 & 0.3 & 0.3 & 0.4 & 0.9 \\
\hline \multirow[t]{3}{*}{ transfers } & $e_{1}^{4}$ & 0.52 & -0.4 & -0.3 & -0.2 & -0.1 & 0.0 & 0.5 & 0.1 & 0.1 & 0.2 & 0.2 & 0.3 & 0.8 \\
\hline & $e_{1}^{5}$ & 0.97 & -0.5 & -0.5 & -0.4 & -0.3 & -0.2 & 0.5 & -0.2 & -0.2 & -0.1 & 0.0 & 0.1 & 0.8 \\
\hline & $m=2$ & & 0.5 & 0.5 & 0.5 & 0.6 & 0.6 & & 1.1 & 1.1 & 1.0 & 1.0 & 0.9 & \\
\hline Run 1 (b) & $e_{1}^{1}$ & 0.09 & -0.1 & -0.1 & 0.0 & 0.0 & 0.0 & 0.3 & 0.4 & 0.4 & 0.4 & 0.4 & 0.4 & 0.9 \\
\hline Reducing & $e_{1}^{2}$ & 0.18 & -0.2 & -0.1 & -0.1 & 0.0 & 0.0 & 0.4 & 0.3 & 0.3 & 0.3 & 0.4 & 0.4 & 0.8 \\
\hline income & $e_{1}^{3}$ & 0.30 & -0.3 & -0.2 & -0.1 & -0.1 & 0.0 & 0.4 & 0.2 & 0.2 & 0.3 & 0.3 & 0.3 & 0.8 \\
\hline \multirow[t]{3}{*}{ tax rates } & $e_{1}^{4}$ & 0.52 & -0.4 & -0.3 & -0.2 & -0.2 & -0.1 & 0.5 & 0.0 & 0.1 & 0.1 & 0.2 & 0.3 & 0.8 \\
\hline & $e_{1}^{5}$ & 0.97 & -0.6 & -0.5 & -0.4 & -0.3 & -0.2 & 0.5 & -0.2 & -0.2 & -0.1 & 0.0 & 0.1 & 0.9 \\
\hline & $m=2$ & & 0.4 & 0.4 & 0.5 & 0.5 & 0.6 & & 1.0 & 0.9 & 0.9 & 0.9 & 0.9 & \\
\hline
\end{tabular}

The consumption equivalence variation measure, $\%$. Rows, $e_{1}^{1}, \ldots, e_{1}^{5}$, are male wage levels at age 21 from the lowest to the highest, and columns, $e_{2}^{1}, \ldots, e_{2}^{5}$, are female wage levels at age 21 .

husband, $e_{1}^{5}$, would be worse off even in the long run. Married households would be worse off least in the short run and better off most in the long run if the husband's wage rate is lower than the wife's wage rate, e.g., $\left(e_{1}^{1}, e_{2}^{4}\right),\left(e_{1}^{1}, e_{2}^{5}\right)$, and $\left(e_{1}^{2}, e_{2}^{5}\right)$. The welfare gains of single households do not depend significantly on their initial wage levels, but the welfare gains are slightly increasing in wages in the short run.

\subsection{Individual Contributions of Spousal and Survivors Benefits}

This section analyzes the effects of removing spousal benefits and survivors benefits separately, and it discusses the relative importance of these two benefits. As before, the payroll tax rate is kept at the baseline level, and old-age retirement benefits are increased proportionally to balance the Social Security budget each year over the transition path. This section only considers the policy changes that assume increasing lump-sum transfers to balance the rest of the government budget because the overall welfare effect is slightly better in Run 1 (a) than in 1 (b).

The first panel of Table 7 shows the effects of removing spousal benefits. The labor force participation rate of women would increase by $0.5 \%$ in the long run, but the average working hours of female workers would not change. Thus, the total working hours of women would also increase by $0.5 \%$ in the long run. Removing spousal benefits accounts for $33 \%$ of the increase in female working hours when both benefits were removed. The average working hours of male workers would decrease by $0.1 \%$ in the long run, but the 
Table 7: The Effects of Removing Spousal and Survivors Benefits Separately (increasing lump-sum transfers, $\%$ changes from the baseline economy)

\begin{tabular}{|c|c|c|c|c|c|c|c|}
\hline \multirow{2}{*}{ Run 2 (a) Removing spousal benefits } & \multicolumn{6}{|c|}{ Year } & \multirow{2}{*}{ Long Run } \\
\hline & 1 & 6 & 11 & 21 & 51 & 81 & \\
\hline Capital stock (national wealth) & 0.0 & 0.0 & 0.0 & 0.0 & 0.0 & 0.0 & 0.0 \\
\hline Labor supply (in efficiency units) & 0.0 & 0.0 & 0.1 & 0.1 & 0.1 & 0.1 & 0.1 \\
\hline Gross domestic product & 0.0 & 0.0 & 0.0 & 0.1 & 0.1 & 0.1 & 0.1 \\
\hline Welfare of age- 21 households & 0.0 & 0.0 & 0.0 & 0.0 & 0.0 & 0.0 & 0.0 \\
\hline OASI payroll tax revenue & 0.0 & 0.0 & 0.1 & 0.1 & 0.1 & 0.1 & 0.1 \\
\hline OASI benefit adjustment & 1.3 & 1.3 & 1.3 & 1.4 & 1.3 & 1.3 & 1.3 \\
\hline Labor supply: men & 0.0 & 0.0 & 0.0 & 0.0 & 0.0 & 0.0 & 0.0 \\
\hline Labor supply: women & 0.1 & 0.1 & 0.2 & 0.3 & 0.3 & 0.3 & 0.3 \\
\hline Total working hours: men & 0.0 & 0.0 & 0.0 & 0.0 & 0.0 & 0.0 & 0.0 \\
\hline Total working hours: women & 0.2 & 0.2 & 0.3 & 0.4 & 0.5 & 0.5 & 0.5 \\
\hline Labor participation rate: men & 0.0 & 0.0 & 0.0 & 0.0 & 0.0 & 0.0 & 0.0 \\
\hline Labor participation rate: women & 0.1 & 0.2 & 0.3 & 0.4 & 0.5 & 0.5 & 0.5 \\
\hline Average work hours: male workers & 0.0 & 0.0 & 0.0 & -0.1 & -0.1 & -0.1 & -0.1 \\
\hline Average work hours: female workers & 0.0 & 0.0 & 0.0 & 0.0 & 0.0 & 0.0 & 0.0 \\
\hline \multirow{2}{*}{ Run 3 (a) Removing survivors benefits } & \multicolumn{6}{|c|}{ Year } & \multirow{2}{*}{ Long Run } \\
\hline & 1 & 6 & 11 & 21 & 51 & 81 & \\
\hline Capital stock (national wealth) & 0.0 & 0.0 & 0.1 & 0.2 & 0.7 & 0.8 & 0.8 \\
\hline Labor supply (in efficiency units) & 0.0 & 0.1 & 0.1 & 0.2 & 0.2 & 0.2 & 0.2 \\
\hline Gross domestic product & 0.0 & 0.1 & 0.1 & 0.2 & 0.4 & 0.4 & 0.4 \\
\hline Welfare of age- 21 households & 0.0 & 0.1 & 0.1 & 0.2 & 0.4 & 0.5 & 0.5 \\
\hline OASI payroll tax revenue & 0.0 & 0.1 & 0.1 & 0.2 & 0.4 & 0.4 & 0.4 \\
\hline OASI benefit adjustment & 7.1 & 7.1 & 7.1 & 6.8 & 6.6 & 7.0 & 7.0 \\
\hline Labor supply: men & -0.1 & -0.1 & -0.1 & -0.1 & -0.2 & -0.2 & -0.2 \\
\hline Labor supply: women & 0.2 & 0.3 & 0.4 & 0.6 & 0.8 & 0.8 & 0.8 \\
\hline Total working hours: men & -0.1 & -0.1 & -0.2 & -0.2 & -0.3 & -0.3 & -0.3 \\
\hline Total working hours: women & 0.3 & 0.4 & 0.6 & 0.8 & 1.2 & 1.1 & 1.1 \\
\hline Labor participation rate: men & 0.0 & 0.0 & 0.0 & 0.0 & 0.0 & 0.0 & 0.0 \\
\hline Labor participation rate: women & 0.3 & 0.4 & 0.5 & 0.7 & 1.0 & 1.0 & 1.0 \\
\hline Average work hours: male workers & -0.1 & -0.1 & -0.1 & -0.2 & -0.2 & -0.3 & -0.3 \\
\hline Average work hours: female workers & 0.1 & 0.1 & 0.1 & 0.1 & 0.2 & 0.2 & 0.2 \\
\hline
\end{tabular}

total working hours of men would be almost unchanged. The total labor supply in efficiency units would increase by $0.1 \%$, the capital stock would stay at the same level, and total output would increase modestly by $0.1 \%$ in the long run. The welfare of 21 -year-old households would also stay at the same level over the transition path.

The second panel of the same table shows the effect of removing survivors benefits. The labor force participation rate of women would increase by $1.0 \%$ in the long run, and the average working hours of female workers would increase by $0.2 \%$. Thus, the total working hours of women would increase by $1.1 \%$ 
Table 8: Parameter and baseline policy values in the alternative economies

\begin{tabular}{|c|c|c|c|c|c|}
\hline & & $\begin{array}{l}\text { Main } \\
\text { baseline }\end{array}$ & $\begin{array}{l}\text { Higher } \\
\gamma\end{array}$ & $\begin{array}{l}\text { Higher } \\
\rho\end{array}$ & $\begin{array}{l}\text { Higher } \\
\omega\end{array}$ \\
\hline Coefficient of relative risk aversion & $\gamma$ & 2.0 & 4.0 & 2.0 & 2.0 \\
\hline Autocorrelation parameter of log wage & $\rho$ & 0.87 & 0.87 & 0.92 & 0.87 \\
\hline Standard deviation of log wage shocks & $\sigma$ & 0.39 & 0.39 & 0.32 & 0.38 \\
\hline Intrafamily wage correlation & $\omega$ & 0.25 & 0.25 & 0.25 & 0.40 \\
\hline Discount factor & $\beta$ & 0.9804 & 0.9876 & 0.9828 & 0.9798 \\
\hline Growth-adjusted discount factor & $\tilde{\beta}$ & 0.9690 & 0.9546 & 0.9715 & 0.9685 \\
\hline Share parameter of consumption & $\alpha$ & 0.6563 & 0.6335 & 0.6470 & 0.6484 \\
\hline Utility from home production (common) & $\kappa_{1}$ & 0.4427 & 1.3468 & 0.4702 & 0.5411 \\
\hline Utility from home production (child care) & $\kappa_{2}$ & 1.6928 & 3.1494 & 1.5846 & 0.1263 \\
\hline Time cost parameter of female market work & $\kappa$ & 1.1812 & 1.3124 & 1.1739 & 1.0362 \\
\hline Income tax parameters: tax rate limit & $\varphi_{t}$ & 0.3360 & 0.3410 & 0.3343 & 0.3338 \\
\hline married $(m=0)$ : curvature & $\varphi_{m, 1}$ & 0.8564 & 0.8564 & 0.8564 & 0.8564 \\
\hline : scale & $\varphi_{m, 2}$ & 0.3604 & 0.3868 & 0.3618 & 0.3723 \\
\hline single $(m=1,2)$ : curvature & $\varphi_{m, 1}$ & 0.6785 & 0.6785 & 0.6785 & 0.6785 \\
\hline : scale & $\varphi_{m, 2}$ & 0.4575 & 0.4839 & 0.4590 & 0.4694 \\
\hline Maximum taxable earnings & $\vartheta_{\max }$ & 1.8203 & 1.6761 & 1.8119 & 1.7528 \\
\hline Replacement rate threshold: $0.90 \& 0.32$ & $\vartheta_{1}$ & 0.1520 & 0.1399 & 0.1513 & 0.1463 \\
\hline$: 0.32 \& 0.15$ & $\vartheta_{2}$ & 0.9160 & 0.8434 & 0.9118 & 0.8820 \\
\hline Government consumption & $C_{G, t}$ & 8.2962 & 7.6387 & 8.2575 & 7.9881 \\
\hline OASI residual & $T R_{O}$ & 0.2456 & 0.2153 & 0.2266 & 0.2564 \\
\hline Government net worth & $W_{G, t}$ & 15.898 & 14.638 & 15.824 & 15.308 \\
\hline Accidental bequests per working-age person & $q_{t}$ & 0.0209 & 0.0227 & 0.0214 & 0.0198 \\
\hline OASI benefit share: workers benefits & $80.1-81.2 \%$ & $80.5 \%$ & $79.9 \%$ & $79.2 \%$ & $80.5 \%$ \\
\hline : spousal benefits & $4.1-4.3 \%$ & $3.9 \%$ & $4.2 \%$ & $5.0 \%$ & $3.6 \%$ \\
\hline : survivors benefits & $14.7-15.6 \%$ & $15.6 \%$ & $15.8 \%$ & $15.7 \%$ & $15.9 \%$ \\
\hline Variance of log labor income by age & $0.40-1.00$ & $0.46-0.96$ & $0.43-0.93$ & $0.43-0.97$ & $0.48-0.96$ \\
\hline
\end{tabular}

in the long run. Removing survivors benefits accounts for $71 \%$ of the increase in female working hours when both spousal and survivors benefits were removed. The total working hours of men would decrease by $0.3 \%$ in the long run, and the total labor supply in efficiency units would increase by $0.2 \%$. The capital stock and the total output would increase gradually and by $0.8 \%$ and $0.4 \%$, respectively, in the long run. These macroeconomic effects are about the same as those of removing both benefits in Run 1 (a). The welfare effect on age-21 households is also similar. On average, 21-year-old households would be better off by $0.5 \%$ in the long run. 
Table 9: The Long-Run Effects of Removing Spousal and Survivors Benefits in Alternative Economies (\% changes from the baseline economy)

\begin{tabular}{|c|c|c|c|c|c|c|c|c|}
\hline & \multicolumn{2}{|c|}{ Main } & \multicolumn{2}{|c|}{ Higher $\gamma$} & \multicolumn{2}{|c|}{ Higher $\rho$} & \multicolumn{2}{|c|}{ Higher $\omega$} \\
\hline & $1(\mathrm{a})$ & $1(\mathrm{~b})$ & $4(\mathrm{a})$ & $4(\mathrm{~b})$ & $5(\mathrm{a})$ & $5(\mathrm{~b})$ & 6 (a) & $6(\mathrm{~b})$ \\
\hline Capital stock (national wealth) & 0.8 & 1.0 & 1.4 & 1.9 & 1.0 & 1.2 & 0.8 & 1.0 \\
\hline Labor supply (in efficiency units) & 0.3 & 0.4 & 0.4 & 0.5 & 0.4 & 0.4 & 0.3 & 0.4 \\
\hline Gross domestic product & 0.5 & 0.6 & 0.7 & 1.0 & 0.6 & 0.7 & 0.5 & 0.6 \\
\hline Welfare of age- 21 households & 0.5 & 0.4 & 1.2 & 1.0 & 0.6 & 0.5 & 0.5 & 0.4 \\
\hline OASI payroll tax revenue & 0.5 & 0.6 & 0.7 & 0.8 & 0.6 & 0.7 & 0.5 & 0.6 \\
\hline OASI benefit adjustment & 8.3 & 8.3 & 8.8 & 8.9 & 9.8 & 9.9 & 8.0 & 8.1 \\
\hline Labor supply: men & -0.2 & -0.2 & -0.2 & -0.1 & -0.2 & -0.1 & -0.2 & -0.2 \\
\hline Labor supply: women & 1.1 & 1.2 & 1.2 & 1.3 & 1.2 & 1.3 & 1.2 & 1.2 \\
\hline Total working hours: men & -0.3 & -0.3 & -0.3 & -0.2 & -0.2 & -0.1 & -0.3 & -0.3 \\
\hline Total working hours: women & 1.6 & 1.7 & 1.5 & 1.7 & 1.9 & 2.0 & 1.6 & 1.7 \\
\hline Labor participation rate: men & 0.0 & 0.0 & -0.1 & -0.1 & 0.1 & 0.1 & 0.0 & 0.0 \\
\hline Labor participation rate: women & 1.4 & 1.4 & 1.3 & 1.4 & 1.7 & 1.8 & 1.3 & 1.4 \\
\hline Average work hours: male workers & -0.3 & -0.3 & -0.2 & -0.1 & -0.4 & -0.3 & -0.3 & -0.3 \\
\hline Average work hours: female workers & 0.2 & 0.3 & 0.2 & 0.3 & 0.2 & 0.2 & 0.3 & 0.3 \\
\hline
\end{tabular}

${ }^{a}$ Changes as percentages of the baseline income tax revenue.

\section{Policy Reform in the Alternative Baseline Economies}

How would the effects of removing spousal and survivors benefits differ depending on the model assumptions? This section shows the policy effects in three alternative baseline economies: the economy with a higher coefficient of relative risk aversion (Run 4), the economy with a higher persistence in wage shocks (Run 5), and the economy consisting of married couples with a higher wage correlation (Run 6). These baseline economies assume the same target values for the capital-output ratio, the Frisch elasticity of working hours, labor participation rates, income tax revenue as a share of GDP, and factor prices as those in the main baseline economy. Table 8 shows the revised parameter values and the corresponding OASI benefit shares in these alternative baseline economies.

In the first alternative baseline economy, the coefficient of relative risk aversion, $\gamma$, is increased from 2.0 to 4.0. Then, the intra-temporal (intra-household) elasticity of substitution of the husband's work hours for the wife's work hours is also changed, although the Frisch elasticity of the average worker is kept at 0.5 . The elasticity of substitution is decreased to $\frac{1-\bar{h}}{\bar{h}} \frac{1}{1-(1-\alpha)(1-\gamma)}=0.3284$ from 0.4493 . In this baseline economy, the shares of spousal and survivors benefits in the total OASI benefits are $4.2 \%$ and $15.8 \%$, respectively, which are a little higher than the shares in the main baseline economy. 
Table 9 shows the long-run effects of removing spousal and survivors benefits in the three alternative economies as well as the main baseline economy. In Runs 4 (a) and 4 (b), the total working hours of women would increase by $1.5-1.7 \%$ relative to the new baseline economy. The labor participation rate of women would rise by $1.3-1.4 \%$, and the average working hours of female workers would increase by $0.2-0.3 \%$. The increase in the female labor supply is not very different in this alternative economy from the main baseline economy, even though the elasticity of substitution is smaller.

The overall macroeconomic effects are larger than those in Runs 1 (a) and 1 (b). The total labor supply in efficiency units would increase by $0.4-0.5 \%$, the capital stock would increase by $1.4-1.9 \%$, and the total output would increase by $0.7-1.0 \%$ in the long run. The slightly larger change in the total labor supply is explained by the higher wage rate generated by the larger increase in precautionary savings, as the households in the alternative economy are more risk averse. The welfare of 21-year-old households would improve significantly by $1.0-1.2 \%$ in the long run.

In the second alternative baseline economy, the autocorrelation of wages, $\rho$, is increased from 0.87 to 0.92. Then, the new transition matrix single workers that corresponds to $\rho=0.92$ is calculated as

$$
\Pi_{e_{1}, i}=\Pi_{e_{2}, i}=\left(\begin{array}{ccccc}
0.8294 & 0.1706 & 0.0000 & 0.0000 & 0.0000 \\
0.0515 & 0.8162 & 0.1323 & 0.0000 & 0.0000 \\
0.0000 & 0.0868 & 0.8264 & 0.0868 & 0.0000 \\
0.0000 & 0.0000 & 0.1323 & 0.8162 & 0.0515 \\
0.0000 & 0.0000 & 0.0000 & 0.1706 & 0.8294
\end{array}\right)
$$

When the transitory wage shocks are more persistent, workers can predict their future wage rates and OASI primary insurance amounts more accurately before making the decisions on labor participation and working hours. So, the shares of spousal and survivors benefits in total OASI benefits become larger, 5.0\% and $15.8 \%$, respectively, in this alternative economy. Thus, when these benefits are replaced with old-age retirement benefits, the households would likely make larger labor supply and saving responses to the policy change.

In Runs 5 (a) and 5(b), the total working hours of women would increase by $1.9-2.0 \%$ in the long run relative to the new baseline economy. Not surprisingly, the labor supply response is larger than those in Runs 1 (a) and 1 (b). The labor force participation rate of women would increase by $1.7-1.8 \%$ in the long run, and the average working hours of female workers would increase by $0.2 \%$. The macroeconomic and welfare effects of the policy change are also a little larger than those in the main baseline economy. The total 
labor supply in efficiency units would increase by $0.4 \%$, the capital stock would increase by $1.0-1.2 \%$, and the total output would increase by $0.6-0.7 \%$ in the long run. The welfare of 21 -year-old households would improve by $0.5-0.6 \%$ in the long run.

In the third alternative baseline economy, the correlation between the husband's wage and the wife's wage is assumed to be 0.4 , increased from 0.25 in the main baseline economy. Under this assumption, the husband's wage and the wife's wage are relatively close to each other, thus fewer couples would expect to receive spousal benefits. Indeed, the share of spousal benefits in total OASI benefits is decreased to 3.6\%, although the share of survivors benefits is increased to $15.9 \%$, in this new baseline economy. So, the changes in the effect of removing spousal and survivors benefits would be ambiguous.

In Runs 6 (a) and 6(b), the total working hours of women would increase by $1.6-1.7 \%$ in the long run. The labor participation rate of women would increase by $1.3-1.4 \%$, which are very close to the increase rates in the main baseline economy. The average working hours of female workers would increase by $0.3 \%$. Thus, the effect on the total labor supply is not very different from those in the main baseline economy. The total labor supply in efficiency units would increase by $0.3-0.4 \%$ in the long run, the capital stock would increase by $0.8-1.0 \%$, and the total output would increase by $0.5-0.6 \%$. The average welfare of 21 -year-old households would improve by $0.4-0.5 \%$ in the long run.

Overall, the effects of removing spousal and survivors benefits on the female labor supply, macroeconomic variables, and social welfare would depend on the values of several parameters assumed in the baseline economy. However, the effects on the overall macro economy and welfare would not differ greatly in the alternative baseline economies considered above, so long as the shares of spousal and survivors benefits in the baseline economies are consistent with the data.

\section{Concluding Remarks}

This paper extends a standard heterogeneous-agent general-equilibrium OLG model with idiosyncratic wage shocks by incorporating both the joint decision making of married households and the OASI spousal and survivors benefits. The model is calibrated to the current-law U.S. economy and used to analyze the possible labor supply, macroeconomic, and welfare effects of removing the survivors and spousal benefits.

According to the numerical policy experiments, in the long run, the removal of those benefits would increase the labor participation of women by $1.4 \%$ and the average working hours of female workers by 
$0.2-0.3 \%$, thus the policy change would increase the total working hours of women by $1.6-1.7 \%$. The policy change would also increase the overall labor supply, the capital stock, and the total output of the economy. Although its macroeconomic effects are not very large, the model predicts that replacing the spousal and survivors benefits with regular old-age benefits would make all age cohorts-current and future-over the transition path, on average, better off if the budget surplus due to the higher economic activity is redistributed by either increasing lump-sum transfers or cutting marginal income tax rates.

To make the model and the decision making of married couples as simple as possible, this paper assumes a unitary utility model of married households. This means that a husband and a wife are considered fully altruistic to each other and that they jointly choose their optimal consumption, working hours, and savings. Also, this paper does not consider the possibilities of divorce and remarrying, because keeping the historical earnings of ex-spouses as state variables would make the general equilibrium model computationally intractable. Due to precautionary motives, however, the risk of separation would likely affect labor supply and saving decisions. Introducing imperfect altruism, the strategic interactions between a husband and a wife, and marriage and divorce decisions is left for future studies.

In addition to Social Security reform plans, the model developed in this paper could predict the effects of various changes in fiscal policy and technology. The model could address issues such as how much the female labor supply would increase if the wage disparity between men and women was reduced, the effects of private firms changing their policy on health insurance coverage, the ramifications of the government subsidizing the cost of daycare services, and so on. An extended version of the model would also help policymakers weigh the costs and benefits of different designs for the Social Security OASI program.

\section{A Computational Algorithm}

The household's optimization problem in this paper is solved recursively from age $i=I$ to 21 by discretizing the asset space, $A=\left[0, a_{\max }\right]$, into 27 nodes, $\hat{A}=\left\{a^{1}, a^{2}, \ldots, a^{27}\right\}$, the average historical earning space, $B=\left[0, b_{\max }\right]$, into 15 nodes each, $\hat{B}=\left\{b^{1}, b^{2}, \ldots, b^{15}\right\}$, and the working ability space, $E=\left[0, e_{\max }\right]$, into 5 nodes for a husband and a wife of each age, $\hat{E}_{1, i}=\left\{e_{1, i}^{1}, e_{1, i}^{2}, \ldots, e_{1, i}^{5}\right\}$ and $\hat{E}_{2, i}=$ $\left\{e_{2, i}^{1}, e_{2, i}^{2}, \ldots, e_{2, i}^{5}\right\}$.

Let $\Omega_{t}$ be a time series of vectors of factor prices and government policy variables that describes a future 
path of the aggregate economy,

$$
\boldsymbol{\Omega}_{t}=\left\{r_{s}, w_{s}, C_{G, s}, \operatorname{tr}_{L S, s}, \varphi_{s}, \bar{\tau}_{P, s}, \psi_{s}, W_{G, s}, q_{s}\right\}_{s=t}^{\infty}
$$

The household's value function is shown as $v\left(\mathbf{s}, \mathbf{S}_{t} ; \mathbf{\Psi}_{t}\right)$, and factor prices and the government's endogenous policy variables are shown as $r_{s}\left(\mathbf{S}_{s} ; \mathbf{\Psi}_{s}\right), w_{s}\left(\mathbf{S}_{s} ; \mathbf{\Psi}_{s}\right), \psi_{s}\left(\mathbf{S}_{s} ; \boldsymbol{\Psi}_{s}\right)$, and so on, for $s \geq t$. However, it is impossible to solve the model of this form because the dimension of $\mathbf{S}_{t}$ is infinite. This paper avoids this curse of dimensionality problem, without changing the solution, by replacing $\left(\mathbf{S}_{t}, \Psi_{t}\right)$ with $\boldsymbol{\Omega}_{t}$. Because the model economy does not include aggregate shocks, the time series $\Omega_{t}$ is deterministic and perfectly foreseeable by the household; thus, it will suffice to find the fixed point of $\Omega_{t}$ to solve the model economy for an equilibrium transition path.

This appendix first explains the algorithm to solve the household's optimization problem for each individual state node,

$$
\mathbf{s}=\left(i, a, b_{1}, b_{2}, e_{1}, e_{2}, m\right) \in\{1,2, \ldots, I\} \times \hat{A} \times \hat{B}^{2} \times \hat{E}_{1, i} \times \hat{E}_{2, i} \times\{0,1,2\},
$$

taking $\Omega_{t}$ as given. The appendix next explains the algorithm to find the household's labor participation decisions. For numerical methods used to solve a Kuhn-Tucker condition for a household's optimal decision, see Judd (1998) and Miranda and Fackler (2002). For a more general algorithm to compute steady-state equilibrium and an equilibrium transition path, see Nishiyama and Smetters (2014).

\section{A.1 Algorithm to Solve the Household Problem}

The household's optimization problem can be solved backward from $i=I$ to 21 by assuming the

terminal value $\left.v\left(\mathbf{s} ; \boldsymbol{\Omega}_{t+1}\right)\right|_{i=I+1}=0$. Let $\hat{v}\left(\mathbf{s} ; \boldsymbol{\Omega}_{t}\right)$ be the value function without the current utility from home production, $\chi\left(h_{1}, h_{2}, m, n_{m, i}\right)$. The household's problem at age $i$ in period $t$ is modified to

$$
\hat{v}\left(\mathbf{s} ; \boldsymbol{\Omega}_{t}\right)=\max _{c, l_{1}, l_{2}}\left\{u\left(c, l_{1}, l_{2} ; m\right)+\tilde{\beta} E\left[v\left(\mathbf{s}^{\prime} ; \boldsymbol{\Omega}_{t+1}\right) \mid \mathbf{s}\right]\right\}
$$

subject to the constraints for the decision variables,

$$
0<c \leq c_{\max }, \quad h_{1}=1-l_{1}, \quad h_{2}=1-\kappa n_{m, i}-l_{2},
$$




$$
\begin{aligned}
& 0<l_{1} \leq 1 \quad \text { if } m \neq 2, \quad l_{1}=1 \quad \text { if } m=2, \\
& 0<l_{2} \leq 1-\kappa n_{m, i} \quad \text { if } m \neq 1, \quad l_{2}=1-\kappa n_{m, i} \quad \text { if } m=1,
\end{aligned}
$$

and the law of motion of the state variables,

$$
\begin{aligned}
\mathbf{s}^{\prime}= & \left(i+1, a^{\prime}, b_{1}^{\prime}, b_{2}^{\prime}, e_{1}^{\prime}, e_{2}^{\prime}, m^{\prime}\right), \\
c_{\max }= & \left(1+r_{t}\right) a+w_{t} e_{1} h_{1}+w_{t} e_{2} h_{2}-\tau_{I, t}\left(r_{t} a+w_{t} e_{1} h_{1}+w_{t} e_{2} h_{2} ; m, n_{m, i}\right)-\tau_{P, t}\left(w_{t} e_{1} h_{1}, w_{t} e_{2} h_{2}\right) \\
& +t_{S S, t}\left(i, b_{1}, b_{2}, m\right)+\left(1+\mathbf{1}_{\{m=0\}}\right)\left(t r_{L S, t}+\mathbf{1}_{\left\{i<I_{R}\right\}} q_{t}\right)-(1+\mu) a_{\min }^{\prime}(\mathbf{s}), \\
a^{\prime}= & \frac{1}{1+\mu}\left(c_{\max }-c\right)+a_{\min }^{\prime}(\mathbf{s}), \\
b_{1}^{\prime}= & \mathbf{1}_{\left\{i<I_{R}, m \neq 2\right\}} \frac{1}{i-20}\left[(i-21) b_{1}+\min \left(w_{t} e_{j} h_{1}, \vartheta_{\max }\right)\right]+\mathbf{1}_{\left\{i \geq I_{R} \text { or } m=2\right\}} b_{1}, \\
b_{2}^{\prime}= & \mathbf{1}_{\left\{i<I_{R}, m \neq 1\right\}} \frac{1}{i-20}\left[(i-21) b_{2}+\min \left(w_{t} e_{j} h_{2}, \vartheta_{\max }\right)\right]+\mathbf{1}_{\left\{i \geq I_{R} \text { or } m=1\right\}} b_{2} .
\end{aligned}
$$

Let the objective function be

$$
f\left(c, l_{1}, l_{2} ; \mathbf{s}, \boldsymbol{\Omega}_{t}\right)=u\left(c, l_{1}, l_{2} ; m\right)+\tilde{\beta} E\left[v\left(\mathbf{s}^{\prime} ; \boldsymbol{\Omega}_{t+1}\right) \mid \mathbf{s}\right] .
$$

The first-order conditions for an interior solution are then

$$
\begin{array}{ll}
\text { (18) } & f_{1}\left(c, l_{1}, l_{2} ; \mathbf{s}, \boldsymbol{\Omega}_{t}\right)=u_{1}\left(c, l_{1}, l_{2} ; m\right)-\frac{\tilde{\beta}}{1+\mu} E\left[v_{a}\left(\mathbf{s}^{\prime} ; \boldsymbol{\Omega}_{t+1}\right) \mid \mathbf{s}\right]=0, \\
\text { (19) } \quad & f_{2}\left(c, l_{1}, l_{2} ; \mathbf{s}, \boldsymbol{\Omega}_{t}\right)=u_{2}\left(c, l_{1}, l_{2} ; m\right) \\
& -w_{t} e_{1}\left[1-\tau_{I, t}^{\prime}\left(r_{t} a+w_{t} e_{1} h_{1}+w_{t} e_{2} h_{2} ; m, n_{m, i}\right)-\tau_{P, 1, t}\left(w_{t} e_{1} h_{1}, w_{t} e_{2} h_{2}\right)\right] u_{1}\left(c, l_{1}, l_{2} ; m\right) \\
& -\mathbf{1}_{\left\{i<I_{R}, w_{t} e_{1} h_{1}<\vartheta_{\max }\right\}} \frac{w_{t} e_{1}}{i-20} \tilde{\beta} E\left[v_{b_{1}}\left(\mathbf{s}^{\prime} ; \boldsymbol{\Omega}_{t+1}\right) \mid \mathbf{s}\right]=0, \\
\text { (20) } & f_{3}\left(c, l_{1}, l_{2} ; \mathbf{s}, \boldsymbol{\Omega}_{t}\right)=u_{3}\left(c, l_{1}, l_{2} ; m\right) \\
& -w_{t} e_{2}\left[1-\tau_{I, t}^{\prime}\left(r_{t} a+w_{t} e_{1} h_{1}+w_{t} e_{2} h_{2} ; m, n_{m, i}\right)-\tau_{P, 2, t}\left(w_{t} e_{1} h_{1}, w_{t} e_{2} h_{2}\right)\right] u_{1}\left(c, l_{1}, l_{2} ; m\right) \\
& -\mathbf{1}_{\left\{i<I_{R}, w_{t} e_{2} h_{2}<\vartheta_{\max }\right\}} \frac{w_{t} e_{2}}{i-20} \tilde{\beta} E\left[v_{b_{2}}\left(\mathbf{s}^{\prime} ; \boldsymbol{\Omega}_{t+1}\right) \mid \mathbf{s}\right]=0,
\end{array}
$$

where $\tau_{I, t}^{\prime}\left(r_{t} a+w_{t} e_{1} h_{1}+w_{t} e_{2} h_{2} ; m, n_{m, i}\right)$ and $\tau_{P, k, t}\left(w_{t} e_{1} h_{1}, w_{t} e_{2} h_{2}\right)$ are the marginal income tax rate and the marginal payroll tax rate with respect to the $k$ th argument, respectively. The equation $(18)$ is the Euler 
equation, and the equations (19) and (20) are the marginal rate of substitution conditions of consumption for leisure.

With the inequality constraints for the decision variables, the Kuhn-Tucker conditions of the household's problem are expressed as the following nonlinear complementarity problem,

$$
\begin{array}{llll}
f_{1}\left(c, l_{1}, l_{2} ; \mathbf{s}, \boldsymbol{\Omega}_{t}\right)=0 & \text { if } \quad 0<c<c_{\max }, & >0 & \text { if } \quad c=c_{\max } \\
f_{2}\left(c, l_{1}, l_{2} ; \mathbf{s}, \boldsymbol{\Omega}_{t}\right)=0 & \text { if } \quad 0<l_{1}<1, & >0 & \text { if } \quad l_{1}=1, \\
f_{3}\left(c, l_{1}, l_{2} ; \mathbf{s}, \boldsymbol{\Omega}_{t}\right)=0 & \text { if } \quad 0<l_{2}<1-\kappa n_{m, i}, & >0 & \text { if } \quad l_{2}=1-\kappa n_{m, i},
\end{array}
$$

which is expressed more compactly as the nonlinear system of equations,

(21) $\min \left\{\max \left[\left(\begin{array}{l}f_{1}\left(c, l_{1}, l_{2} ; \mathbf{s}, \boldsymbol{\Omega}_{t}\right) / u_{1}\left(c, l_{1}, l_{2} ; m\right) \\ f_{2}\left(c, l_{1}, l_{2} ; \mathbf{s}, \boldsymbol{\Omega}_{t}\right) / u_{1}\left(c, l_{1}, l_{2} ; m\right) \\ f_{3}\left(c, l_{1}, l_{2} ; \mathbf{s}, \boldsymbol{\Omega}_{t}\right) / u_{1}\left(c, l_{1}, l_{2} ; m\right)\end{array}\right),\left(\begin{array}{c}\varepsilon-c \\ \varepsilon-l_{1} \\ \varepsilon-l_{2}\end{array}\right)\right],\left(\begin{array}{c}c_{\max }-c \\ 1-l_{1} \\ 1-\kappa n_{m, i}-l_{2}\end{array}\right)\right\}=\mathbf{0}$,

where $\varepsilon$ is a small positive number. Following Miranda and Fackler (2002), the $\min (u, v)$ and $\max (u, v)$ operators are replaced with the Fischer-Burmeister function and its variation,

$$
\phi^{-}(u, v) \equiv u+v-\sqrt{u^{2}+v^{2}}, \quad \phi^{+}(u, v) \equiv u+v+\sqrt{u^{2}+v^{2}},
$$

respectively, to make the above system of equations differentiable without altering the solutions. The equation 21) can be solved for $\hat{c}\left(\mathbf{s} ; \boldsymbol{\Omega}_{t}\right), \hat{l}_{1}\left(\mathbf{s} ; \boldsymbol{\Omega}_{t}\right)$, and $\hat{l}_{2}\left(\mathbf{s} ; \boldsymbol{\Omega}_{t}\right)$ by using a Newton-type nonlinear equation solver, NEQNF, of the IMSL Fortran Numerical Library. Then, the other decisions, $\hat{h}_{1}\left(\mathbf{s} ; \boldsymbol{\Omega}_{t}\right), \hat{h}_{2}\left(\mathbf{s} ; \boldsymbol{\Omega}_{t}\right)$, $\hat{a}^{\prime}\left(\mathbf{s} ; \boldsymbol{\Omega}_{t}\right), \hat{b}_{1}^{\prime}\left(\mathbf{s} ; \boldsymbol{\Omega}_{t}\right)$, and $\hat{b}_{2}^{\prime}\left(\mathbf{s} ; \boldsymbol{\Omega}_{t}\right)$ are obtained 18

Once the optimal decisions are obtained, next the value of the household with state $\mathbf{s}$ in period $t$, before the utility from home production, is calculated as

$$
\hat{v}\left(\mathbf{s} ; \boldsymbol{\Omega}_{t}\right)=u\left(\hat{c}\left(\mathbf{s} ; \boldsymbol{\Omega}_{t}\right), \hat{l}_{1}\left(\mathbf{s} ; \boldsymbol{\Omega}_{t}\right), \hat{l}_{2}\left(\mathbf{s} ; \boldsymbol{\Omega}_{t}\right) ; m\right)+\tilde{\beta} E\left[v\left(\mathbf{s}^{\prime} ; \boldsymbol{\Omega}_{t+1}\right) \mid \mathbf{s}\right]
$$

\footnotetext{
${ }^{18}$ NEQNF uses a modified Powell hybrid algorithm and a finite-difference approximation to the Jacobian.
} 
and the corresponding marginal values are calculated as

$$
\begin{aligned}
\hat{v}_{a}\left(\mathbf{s} ; \boldsymbol{\Omega}_{t}\right)=\left[1+r_{t}(1\right. & \left.\left.-\tau_{I, t}^{\prime}\left(r_{t} a+w_{t} e_{1} \hat{h}_{1}\left(\mathbf{s} ; \boldsymbol{\Omega}_{t}\right)+w_{t} e_{2} \hat{h}_{2}\left(\mathbf{s} ; \boldsymbol{\Omega}_{t}\right)\right) ; m, n_{m, i}\right)\right] \\
& \times u_{c}\left(\hat{c}\left(\mathbf{s} ; \boldsymbol{\Omega}_{t}\right), \hat{l}_{1}\left(\mathbf{s} ; \boldsymbol{\Omega}_{t}\right), \hat{l}_{2}\left(\mathbf{s} ; \boldsymbol{\Omega}_{t}\right) ; m\right), \\
\hat{v}_{b_{1}}\left(\mathbf{s} ; \boldsymbol{\Omega}_{t}\right)=\operatorname{tr}_{S S, b_{1}, t}( & \left.i, b_{1}, b_{2}, m\right) u_{c}\left(\hat{c}\left(\mathbf{s} ; \boldsymbol{\Omega}_{t}\right), \hat{l}_{1}\left(\mathbf{s} ; \boldsymbol{\Omega}_{t}\right), \hat{l}_{2}\left(\mathbf{s} ; \boldsymbol{\Omega}_{t}\right) ; m\right) \\
& +\left(\mathbf{1}_{\left\{i<I_{R}, m \neq 2\right\}} \frac{i-21}{i-20}+\mathbf{1}_{\left\{i \geq I_{R} \text { or } m=2\right\}}\right) \tilde{\beta} E\left[v_{b_{1}}\left(\mathbf{s}^{\prime} ; \boldsymbol{\Omega}_{t+1}\right) \mid \mathbf{s}\right], \\
\hat{v}_{b_{2}}\left(\mathbf{s} ; \boldsymbol{\Omega}_{t}\right)=\operatorname{tr}_{S S, b_{2}, t}( & \left.i, b_{1}, b_{2}, m\right) u_{c}\left(c\left(\mathbf{s} ; \boldsymbol{\Omega}_{t}\right), l_{1}\left(\mathbf{s} ; \boldsymbol{\Omega}_{t}\right), l_{2}\left(\mathbf{s} ; \boldsymbol{\Omega}_{t}\right) ; m\right) \\
+ & \left(\mathbf{1}_{\left\{i<I_{R}, m \neq 1\right\}} \frac{i-21}{i-20}+\mathbf{1}_{\left\{i \geq I_{R} \text { or } m=1\right\}}\right) \tilde{\beta} E\left[v_{b_{2}}\left(\mathbf{s}^{\prime} ; \boldsymbol{\Omega}_{t+1}\right) \mid \mathbf{s}\right],
\end{aligned}
$$

where $\operatorname{tr}_{S S, b_{1}, t}\left(i, b_{1}, b_{2}, m\right)$ and $\operatorname{tr}_{S S, b_{2}, t}\left(i, b_{1}, b_{2}, m\right)$ are the marginal OASI benefits corresponding to $b_{1}$ and $b_{2}$, respectively. These marginal values are used to solve the optimization problem of age $i-1$ in period $t-1$. The marginal benefit functions in the baseline economy are obtained as

$$
\begin{aligned}
& \operatorname{tr}_{S S, b_{1}, t}\left(i, b_{1}, b_{2}, m\right) \\
& = \begin{cases}\psi_{t}\left[\mathbf{1}_{\left\{\psi\left(i, b_{1}\right) \geq 0.5 \psi\left(i, b_{2}\right)\right\}} \psi_{b}\left(i, b_{1}\right)+\mathbf{1}_{\left\{\psi\left(i, b_{1}\right)>2.0 \psi\left(i, b_{2}\right)\right\}} 0.5 \psi_{b}\left(i, b_{1}\right)\right] & \text { if } m=0, \\
\psi_{t} \mathbf{1}_{\left\{\psi\left(i, b_{1}\right) \geq \psi\left(i, b_{2}\right)\right\}} \psi_{b}\left(i, b_{1}\right) & \text { if } m=1,2,\end{cases} \\
& \operatorname{tr}_{S S, b_{2}, t}\left(i, b_{1}, b_{2}, m\right) \\
& = \begin{cases}\psi_{t}\left[\mathbf{1}_{\left\{\psi\left(i, b_{2}\right) \geq 0.5 \psi\left(i, b_{1}\right)\right\}} \psi_{b}\left(i, b_{2}\right)+\mathbf{1}_{\left\{\psi\left(i, b_{2}\right)>2.0 \psi\left(i, b_{1}\right)\right\}} 0.5 \psi_{b}\left(i, b_{2}\right)\right] & \text { if } m=0, \\
\psi_{t} \mathbf{1}_{\left\{\psi\left(i, b_{2}\right) \geq \psi\left(i, b_{1}\right)\right\}} \psi_{b}\left(i, b_{2}\right) & \text { if } m=1,2,\end{cases}
\end{aligned}
$$

where $\psi_{b}\left(i, b_{j}\right)$ is the marginal primary insurance amount (PIA) function,

$$
\psi_{b}\left(i, b_{j}\right)=\mathbf{1}_{\left\{i \geq I_{R}\right\}}(1+\mu)^{60-i}\left\{\mathbf{1}_{\left\{b_{j}<\vartheta_{1}\right\}} 0.90+\mathbf{1}_{\left\{\vartheta_{1} \leq b_{j}<\vartheta_{2}\right\}} 0.32+\mathbf{1}_{\left\{\vartheta_{2} \leq b_{j}\right\}} 0.15\right\}
$$

for $j=1$ and 2. The marginal benefit functions in the economy without spousal and survivors benefits are

$$
\begin{aligned}
& \operatorname{tr}_{S S, b_{1}, t}^{1}\left(i, b_{1}, b_{2}, m\right)=\psi_{t} \psi_{b}\left(i, b_{1}\right) \quad \text { if } m=0 \text { or } 1, \quad=0 \quad \text { if } m=2 \text {, } \\
& \operatorname{tr}_{S S, b_{2}, t}^{1}\left(i, b_{1}, b_{2}, m\right)=\psi_{t} \psi_{b}\left(i, b_{2}\right) \quad \text { if } m=0 \text { or } 2, \quad=0 \quad \text { if } m=1 .
\end{aligned}
$$




\section{A.2 Algorithm to Find Labor Participation Decisions}

Let's assume the household is married $(m=0)$. This paper first solves the household problem without any restriction for $\hat{c}\left(\mathbf{s} ; \boldsymbol{\Omega}_{t}\right), \hat{h}_{1}\left(\mathbf{s} ; \boldsymbol{\Omega}_{t}\right), \hat{h}_{2}\left(\mathbf{s} ; \boldsymbol{\Omega}_{t}\right), \hat{a}^{\prime}\left(\mathbf{s} ; \boldsymbol{\Omega}_{t}\right), \hat{b}_{1}^{\prime}\left(\mathbf{s} ; \boldsymbol{\Omega}_{t}\right), \hat{b}_{2}^{\prime}\left(\mathbf{s} ; \boldsymbol{\Omega}_{t}\right), \hat{v}\left(\mathbf{s} ; \boldsymbol{\Omega}_{t}\right), \hat{v}_{a}\left(\mathbf{s} ; \boldsymbol{\Omega}_{t}\right)$, $\hat{v}_{b_{1}}\left(\mathbf{s} ; \boldsymbol{\Omega}_{t}\right)$, and $\hat{v}_{b_{2}}\left(\mathbf{s} ; \boldsymbol{\Omega}_{t}\right)$. If $\hat{h}_{1}\left(\mathbf{s} ; \boldsymbol{\Omega}_{t}\right)=0$ or $\hat{h}_{2}\left(\mathbf{s} ; \boldsymbol{\Omega}_{t}\right)=0$ or both, the expected value of this household, with additional utility from staying at home, is set as

$$
v\left(\mathbf{s} ; \boldsymbol{\Omega}_{t}\right)=\hat{v}\left(\mathbf{s} ; \boldsymbol{\Omega}_{t}\right)+E\left[\chi\left(\hat{h}_{1}\left(\mathbf{s} ; \boldsymbol{\Omega}_{t}\right), \hat{h}_{2}\left(\mathbf{s} ; \boldsymbol{\Omega}_{t}\right) ; m, n_{m, i}\right)\right]
$$

and the decision rules and value functions are set as

$$
\begin{array}{lll}
c\left(\mathbf{s} ; \boldsymbol{\Omega}_{t}\right)=\hat{c}\left(\mathbf{s} ; \boldsymbol{\Omega}_{t}\right), & h_{1}\left(\mathbf{s} ; \boldsymbol{\Omega}_{t}\right)=\hat{h}_{1}\left(\mathbf{s} ; \boldsymbol{\Omega}_{t}\right), & h_{2}\left(\mathbf{s} ; \boldsymbol{\Omega}_{t}\right)=\hat{h}_{2}\left(\mathbf{s} ; \boldsymbol{\Omega}_{t}\right), \\
a^{\prime}\left(\mathbf{s} ; \boldsymbol{\Omega}_{t}\right)=\hat{a}^{\prime}\left(\mathbf{s} ; \boldsymbol{\Omega}_{t}\right), & b_{1}^{\prime}\left(\mathbf{s} ; \boldsymbol{\Omega}_{t}\right)=\hat{b}_{1}^{\prime}\left(\mathbf{s} ; \boldsymbol{\Omega}_{t}\right), & b_{2}^{\prime}\left(\mathbf{s} ; \boldsymbol{\Omega}_{t}\right)=\hat{b}_{2}^{\prime}\left(\mathbf{s} ; \boldsymbol{\Omega}_{t}\right), \\
v_{a}\left(\mathbf{s} ; \boldsymbol{\Omega}_{t}\right)=\hat{v}_{a}\left(\mathbf{s} ; \boldsymbol{\Omega}_{t}\right), & v_{b_{1}}\left(\mathbf{s} ; \boldsymbol{\Omega}_{t}\right)=\hat{v}_{b_{1}}\left(\mathbf{s} ; \boldsymbol{\Omega}_{t}\right), & v_{b_{2}}\left(\mathbf{s} ; \boldsymbol{\Omega}_{t}\right)=\hat{v}_{b_{2}}\left(\mathbf{s} ; \boldsymbol{\Omega}_{t}\right) .
\end{array}
$$

If $\hat{h}_{1}\left(\mathbf{s} ; \boldsymbol{\Omega}_{t}\right) \geq \hat{h}_{2}\left(\mathbf{s} ; \boldsymbol{\Omega}_{t}\right)>0$, this paper solves the above household problem again with an additional constraint $h_{2}=0$ for $\hat{c}\left(\mathbf{s} ; \boldsymbol{\Omega}_{t}, h_{2}=0\right), \hat{h}_{1}\left(\mathbf{s} ; \boldsymbol{\Omega}_{t}, h_{2}=0\right), \hat{a}^{\prime}\left(\mathbf{s} ; \boldsymbol{\Omega}_{t}, h_{2}=0\right), \hat{b}_{1}^{\prime}\left(\mathbf{s} ; \boldsymbol{\Omega}_{t}, h_{2}=0\right), \hat{b}_{2}^{\prime}\left(\mathbf{s} ; \boldsymbol{\Omega}_{t}, h_{2}=\right.$ $0), \hat{v}\left(\mathbf{s} ; \boldsymbol{\Omega}_{t}, h_{2}=0\right), \hat{v}_{a}\left(\mathbf{s} ; \boldsymbol{\Omega}_{t}, h_{2}=0\right), \hat{v}_{b_{1}}\left(\mathbf{s} ; \boldsymbol{\Omega}_{t}, h_{2}=0\right)$, and $\hat{v}_{b_{2}}\left(\mathbf{s} ; \boldsymbol{\Omega}_{t}, h_{2}=0\right)$. Then, the expected value with additional utility from staying at home is obtained as

$$
\begin{aligned}
v\left(\mathbf{s} ; \boldsymbol{\Omega}_{t}\right) & =\operatorname{Pr}(\tilde{\chi} \leq d) \hat{v}\left(\mathbf{s} ; \boldsymbol{\Omega}_{t}\right)+\operatorname{Pr}(\tilde{\chi}>d)\left\{\hat{v}\left(\mathbf{s} ; \boldsymbol{\Omega}_{t}, h_{2}=0\right)+E[\tilde{\chi} \mid \tilde{\chi}>d]\right\} \\
& =\hat{v}\left(\mathbf{s} ; \boldsymbol{\Omega}_{t}\right)+\operatorname{Pr}(\tilde{\chi}>d) E[\tilde{\chi}-d \mid \tilde{\chi}>d] \\
& =\hat{v}\left(\mathbf{s} ; \boldsymbol{\Omega}_{t}\right)+E\left[(\tilde{\chi}-d)_{+}\right]
\end{aligned}
$$

where $\tilde{\chi}=\chi\left(\hat{h}_{1}\left(\mathbf{s} ; \boldsymbol{\Omega}_{t}, h_{2}=0\right), 0 ; m, n_{m, i}\right), d=\hat{v}\left(\mathbf{s} ; \boldsymbol{\Omega}_{t}\right)-\hat{v}\left(\mathbf{s} ; \boldsymbol{\Omega}_{t}, h_{2}=0\right)$, and

$$
\begin{aligned}
& E\left[(\tilde{\chi}-d)_{+}\right]=\bar{\alpha} \bar{\theta}(1-\Gamma(d / \bar{\theta} ; \bar{\alpha}+1))-d(1-\Gamma(d / \bar{\theta} ; \bar{\alpha})), \\
& \Gamma(\alpha ; x) \equiv \frac{1}{\Gamma(\alpha)} \int_{0}^{x} t^{\alpha-1} e^{-t} d t, \quad \Gamma(\alpha) \equiv \int_{0}^{\infty} t^{\alpha-1} e^{-t} d t, \quad \alpha>0, \quad x>0 .
\end{aligned}
$$


The decision rules and value functions are set as

$$
\begin{aligned}
& \text { (30) }\left\{c\left(\mathbf{s} ; \boldsymbol{\Omega}_{t}\right), h_{1}\left(\mathbf{s} ; \boldsymbol{\Omega}_{t}\right), h_{2}\left(\mathbf{s} ; \boldsymbol{\Omega}_{t}\right), a^{\prime}\left(\mathbf{s} ; \boldsymbol{\Omega}_{t}\right), b_{1}^{\prime}\left(\mathbf{s} ; \boldsymbol{\Omega}_{t}\right), b_{2}^{\prime}\left(\mathbf{s} ; \boldsymbol{\Omega}_{t}\right)\right\} \\
& \quad=\left\{\begin{array}{l}
\left\{\hat{c}\left(\mathbf{s} ; \boldsymbol{\Omega}_{t}\right), \hat{h}_{1}\left(\mathbf{s} ; \boldsymbol{\Omega}_{t}\right), \hat{h}_{2}\left(\mathbf{s} ; \boldsymbol{\Omega}_{t}\right), \hat{a}^{\prime}\left(\mathbf{s} ; \boldsymbol{\Omega}_{t}\right), \hat{b}_{1}^{\prime}\left(\mathbf{s} ; \boldsymbol{\Omega}_{t}\right), \hat{b}_{2}^{\prime}\left(\mathbf{s} ; \boldsymbol{\Omega}_{t}\right)\right\} \quad \text { with prob. } \operatorname{Pr}(\tilde{\chi} \leq d), \\
\left\{\hat{c}\left(\mathbf{s} ; \boldsymbol{\Omega}_{t}, h_{2}=0\right), \hat{h}_{1}\left(\mathbf{s} ; \boldsymbol{\Omega}_{t}, h_{2}=0\right), \hat{h}_{2}\left(\mathbf{s} ; \boldsymbol{\Omega}_{t}, h_{2}=0\right),\right. \\
\left.\hat{a}^{\prime}\left(\mathbf{s} ; \boldsymbol{\Omega}_{t}, h_{2}=0\right), \hat{b}_{1}^{\prime}\left(\mathbf{s} ; \boldsymbol{\Omega}_{t}, h_{2}=0\right), \hat{b}_{2}^{\prime}\left(\mathbf{s} ; \boldsymbol{\Omega}_{t}, h_{2}=0\right)\right\} \quad \text { with prob. } \operatorname{Pr}(\tilde{\chi}>d),
\end{array}\right. \\
& \text { (31) } v_{a}\left(\mathbf{s} ; \boldsymbol{\Omega}_{t}\right)=\operatorname{Pr}(\tilde{\chi} \leq d) \hat{v}_{a}\left(\mathbf{s} ; \boldsymbol{\Omega}_{t}\right)+\operatorname{Pr}(\tilde{\chi}>d) \hat{v}_{a}\left(\mathbf{s} ; \boldsymbol{\Omega}_{t}, h_{2}=0\right), \\
& \text { (32) } v_{b_{1}}\left(\mathbf{s} ; \boldsymbol{\Omega}_{t}\right)=\operatorname{Pr}(\tilde{\chi} \leq d) \hat{v}_{b_{1}}\left(\mathbf{s} ; \boldsymbol{\Omega}_{t}\right)+\operatorname{Pr}(\tilde{\chi}>d) \hat{v}_{b_{1}}\left(\mathbf{s} ; \boldsymbol{\Omega}_{t}, h_{2}=0\right), \\
& \text { (33) } v_{b_{1}}\left(\mathbf{s} ; \boldsymbol{\Omega}_{t}\right)=\operatorname{Pr}(\tilde{\chi} \leq d) \hat{v}_{b_{2}}\left(\mathbf{s} ; \boldsymbol{\Omega}_{t}\right)+\operatorname{Pr}(\tilde{\chi}>d) \hat{v}_{b_{2}}\left(\mathbf{s} ; \boldsymbol{\Omega}_{t}, h_{2}=0\right) .
\end{aligned}
$$

If instead $\hat{h}_{2}\left(\mathbf{s} ; \boldsymbol{\Omega}_{t}\right)>\hat{h}_{1}\left(\mathbf{s} ; \boldsymbol{\Omega}_{t}\right)>0$, then the above household problem with an additional constraint $h_{1}=$

0 is solved for $\hat{c}\left(\mathbf{s} ; \boldsymbol{\Omega}_{t}, h_{1}=0\right), \hat{h}_{1}\left(\mathbf{s} ; \boldsymbol{\Omega}_{t}, h_{1}=0\right), \hat{a}^{\prime}\left(\mathbf{s} ; \boldsymbol{\Omega}_{t}, h_{1}=0\right), \hat{b}_{1}^{\prime}\left(\mathbf{s} ; \boldsymbol{\Omega}_{t}, h_{1}=0\right), \hat{b}_{2}^{\prime}\left(\mathbf{s} ; \boldsymbol{\Omega}_{t}, h_{1}=0\right)$, $\hat{v}\left(\mathbf{s} ; \boldsymbol{\Omega}_{t}, h_{1}=0\right), \hat{v}_{a}\left(\mathbf{s} ; \boldsymbol{\Omega}_{t}, h_{1}=0\right), \hat{v}_{b_{1}}\left(\mathbf{s} ; \boldsymbol{\Omega}_{t}, h_{1}=0\right)$, and $\hat{v}_{b_{2}}\left(\mathbf{s} ; \boldsymbol{\Omega}_{t}, h_{1}=0\right)$; and the rest of the algorithm is the same as above. The algorithm is similar when the household is single $(m=1$ or $m=2)$.

\section{References}

[1] Attanasio, Orazio, Hamish Low, and Virginia Sánchez-Marcos. 2008. "Explaining Changes in Female Labor Supply in a Life-Cycle Model.” American Economic Review, 98(4): 1517-22.

[2] Auerbach, Alan J., and Laurence J. Kotlikoff. 1987. Dynamic Fiscal Policy. Cambridge, UK: Cambridge University Press.

[3] Bernheim, Douglas, Lorenzo Forni, Jagadeesh Gokhale, and Laurence J. Kotlikoff. 2003. "The Mismatch Between Life Insurance Holdings and Financial Vulnerabilities: Evidence from the Health and Retirement Study." American Economic Review, 93(1): 354-65.

[4] Bethencourt, Carlos, and Virginia Sánchez-Marcos. 2014. “The Effect of Public Pensions on Women’s Labor Market Participation over a Full Life-Cycle.” Manuscript, University of La Laguna and University of Cantabria. 
[5] Brown, Jeffrey R., and James M. Poterba. 2000. "Joint Life Annuities and Annuity Demand by Married Couples." Journal of Risk and Insurance, 67(4): 527-54.

[6] U.S. Bureau of Labor Statistics. 2013a. "Civilian Labor Force Participation Rates by Age, Sex, Race, and Ethnicity." BLS Employment Projections. http://www.bls.gov/emp/ep_table_303. htm (Last accessed on September 3, 2014).

[7] U.S. Bureau of Labor Statistics. 2013b. "Highlights of Women's Earnings in 2012.” BLS Report 1045.

[8] Conesa, Juan C., Sagiri Kitao, and Dirk Krueger. 2009. “Taxing Capital? Not a Bad Idea After All!” American Economic Review, 99(1): 25-48.

[9] Conesa, Juan C., and Dirk Krueger. 1999. “Social Security Reform with Heterogeneous Agents.” Review of Economic Dynamics, 2(4): 757-95.

[10] Domeij, David, and Jonathan Heathcote. 2004. "On the Distributional Effects of Reducing Capital Taxes.” International Economic Review, 45 (2): 523-54.

[11] Gouveia, Miguel, and Robert P. Strauss. 1994. "Effective Federal Individual Income Tax Functions: An Exploratory Empirical Analysis.” National Tax Journal, 47(2): 317-39.

[12] Guner, Nezih, Remzi Kaygusuz, and Gustavo Ventura. 2012a. "Taxing Women: A Macroeconomic Analysis." Journal of Monetary Economics, 59: 111-28.

[13] Guner, Nezih, Remzi Kaygusuz, and Gustavo Ventura. 2012b. "Taxation and Household Labour Supply." Review of Economic Studies, 79: 1113-49.

[14] Hong, Jay H., and José-Víctor Ríos-Rull. 2007. "Social Security, Life Insurance and Annuities for Families.” Journal of Monetary Economics, 54: 118-40.

[15] Huggett, Mark, and Juan Carlos Parra. 2010. "How Well Does the U.S. Social Insurance System Provide Social Insurance?” Journal of Political Economy, 118(1): 76-112.

[16] Hyslop, Dean R. 2001. "Rising U.S. Earnings Inequality and Family Labor Supply: The Covariance Structure of Intrafamily Earnings.” American Economic Review, 91(4): 755-77.

[17] İmrohoroğlu, Aişe, Selahattin İmrohoroğlu, and Douglas Joines. 1995. "A Life Cycle Analysis of Social Security.” Economic Theory, 6(1): 83-114. 
[18] Judd, Kenneth L. 1998. Numerical Methods in Economics. Cambridge, MA: MIT Press.

[19] Kaygusuz, Remzi. 2010. “Taxes and Female Labor Supply.” Review of Economic Dynamics, 13:72541.

[20] Kaygusuz, Remzi. 2014. "Social Security and Two-Earner Households.” Manuscript, Sabanc1 University.

[21] Kotlikoff, Laurence J., Kent Smetters, and Jan Walliser. 1999. "Privatizing Social Security in the United States—Comparing the Options." Review of Economic Dynamics, 2(4): 532-74.

[22] Kotlikoff, Laurence J., and Avia Spivak. 1981. "The Family as an Incomplete Annuities Market." Journal of Political Economy, 89(2): 372-91.

[23] Miranda, Mario J., and Paul L. Fackler. 2002. “Applied Computational Economics and Finance,” Cambridge, MA: MIT Press.

[24] Nishiyama, Shinichi, and Kent Smetters. 2007. "Does Social Security Privatization Produce Efficiency Gains?" Quarterly Journal of Economics, 122(4): 1677-719.

[25] Nishiyama, Shinichi, and Kent Smetters. 2014. "Analyzing Fiscal Policies in a Heterogeneous-Agent Overlapping-Generations Economy.” Kenneth L. Judd and Karl Schmedders, eds., Handbook of Computational Economics, Volume 3, Chapter 3.

[26] Olivetti, Claudia. 2006. "Changes in Women's Hours of Market Work: The Role of Returns to Experience." Review of Economic Dynamics, 9: 557-87.

[27] Social Security Administration. 2014. "Annual Statistical Supplement to the Social Security Bulletin, 2013.” SSA Publication 13-11700.

[28] United Nations. 2008. “World Fertility Data 2008: Period Fertility Indicators.” United Nations, http: //www.un.org/esa/population/publications/WFD\%202008/Main.html. 